\title{
GEOSUL
}

\section{EVOLUÇÃO DOS ÍNDICES SOCIOECONÔMICOS E FATORES MOTIVADORES DE INVESTIMENTOS NO MUNICÍPIO DE JARAGUÁ DO SUL/SC}

\author{
Paulo Rogério Alves Brene ${ }^{1}$ \\ Ronaldo Raemy Rangel ${ }^{2}$ \\ Renan Henrique Luquini ${ }^{3}$ \\ Umberto Antônio Sesso Filho ${ }^{4}$ \\ Cleverson Neves ${ }^{5}$
}

\begin{abstract}
Resumo: O objetivo deste trabalho é analisar os indicadores socioeconômicos do município de Jaraguá do Sul destacando a evolução da estrutura produtiva, assim como levantar, a partir da perspectiva do empresariado do município, os fatores motivacionais de investimentos. No tocante à metodologia, destacam-se o uso de dados secundários de órgãos de pesquis e a pesquisa estruturada (entrevistas), e como ferramenta analítica utilizou-se do cálculo dos índices de correlação, mais especificamente os de Pearson (valor) e de Spearman (posto/ordem). O foco do cálculo desses indicadores foi medir a proximidade das características de Jaraguá do Sul com outros municípios. Como resultado, destaca-se que se deve ter reserva quanto à comparação entre o município de Jaraguá do Sul e outros do estado de Santa Catarina e que a estrutura produtiva observada no município está acima da média nacional.
\end{abstract}

Palavras-chave: Evolução Socioeconômica; Jaraguá do Sul/SC; Índices de Correlação; Perspectivas Empresariais; Fatores Motivadores de Investimento

\section{EVOLUTION OF SOCIOECONOMIC INDICES AND MOTIVATING FACTORS FOR INVESTMENTS IN THE CITY OF JARAGUÁ DO SUL/SC}

\begin{abstract}
The aim of this work is to analyze the socioeconomic indicators of the city of Jaraguá do Sul highlighting the evolution of the productive structure, as well as to raise the motivational factors of investments from the perspective of the municipal entrepreneurship. Regarding methodology, we highlight the use of secondary data from research agencies, structured research (interviews) and as an analytical tool was used the calculation of correlation indexes, more specifically those of Pearson (value) and Spearman (rank /order). The focus of the calculation of these indicators was to measure the proximity of the characteristics of Jaraguá do Sul with other municipalities. As a result, it should be noted that there should be a reservation regarding the comparison between the municipality of Jaraguá do Sul and others in the state of Santa Catarina and that the productive structure observed in the municipality is above the national average.
\end{abstract}

\footnotetext{
${ }^{1}$ Doutor em Desenvolvimento Econômico - PPGDE/UFPR. Professor do curso de ciências econômicas da UENP. E-mail: paulobrene@uenp.edu.br.

2 Doutor em Desenvolvimento Econômico - UNICAMP. Professor da Escola Paulista de Negócios e coordenador do Pós-MBA em Inteligência Empresarial FGV. E-mail: ronaldo@ paulistadenegocios.com.br.

${ }^{3}$ Mestre em Economia Regional - UEL. E-mail: rhluquini@gmail.com.

${ }^{4}$ Doutor em Economia Aplicada - ESALQ/USP. Professor do Programa de Mestrado em Economia Regional da UEL.E-mail: umasesso@uel.br.

5 Mestre em Economia Regional - UEL. Professor do curso de ciências econômicas da UEL. E-mail: cleversonneves@uel.br.
} 
Keywords: Socioeconomic Evolution; Jaraguá do Sul/SC; Correlation Indices; Business Perspectives; Investment Motivating Factors

\section{EVOLUCIÓN DE LOS ÍNDICES SOCIOECONÓMICOS Y FACTORES MOTIVADORES DE INVERSIONES EN EL MUNICIPIO DE JARAGUÁ DEL SUR/SC}

Resumen: El objetivo de este trabajo es analizar los indicadores socioeconómicos del municipio de Jaraguá do Sul destacando la evolución de la estructura productiva, así como levantar, a partir de la perspectiva del empresariado del municipio, los factores motivacionales de inversiones. En cuanto a la metodología, se destaca el uso de datos secundarios de órganos de investigación, investigación estructurada (entrevistas) y como herramienta analítica se utilizó del cálculo de los índices de correlación, más específicamente los de Pearson (valor) y de Spearman (puesto / orden). El foco del cálculo de esos indicadores fue medir la proximidad de las características de Jaraguá do Sul con otros municipios. Como resultado, se destaca que se debe tener reserva en cuanto a la comparación entre el municipio de Jaraguá do Sul y otros del estado de Santa Catarina y que la estructura productiva observada en el municipio está por encima de la media nacional.

Palabras clave: Evolución Socioeconómica; Jaraguá do Sul/SC; Índices de correlación; Perspectivas Empresariales; Factores motivadores de inversión

\section{INTRODUÇÃO}

De acordo com os dados da Federação das Indústrias do Estado do Rio de Janeiro (FIRJAN, 2014), os municípios do estado de Santa Catarina apresentam um quadro socioeconômico favorável em consideração as demais localidades no Brasil. Os dados da federação apontam que, para o ano de 2011, “(...) dos seus 293 municípios 95,6\% apresentaram IFDM moderado ou alto (pontuação superior a 0,6 pontos), frente a $60,7 \%$ observados em nível nacional”. Dentre esses municípios é possível destacar Jaraguá do Sul, notório pelo seu parque industrial diversificado e com íntima relação com o mercado mundial, com pontuação de 0,8347 no IFDM (18 ${ }^{\text {a }}$ posição no estado e $137^{\mathrm{a}}$. no Brasil).

Ainda em relação à Jaraguá do Sul, outros aspectos podem ser observados, entre eles os apresentados na pesquisa "Santa Catarina em Números" (SEBRAE/SC, 2010). Nessa pesquisa é possível observar o crescimento populacional do município, que sai de 45,5 mil habitantes em 1980 para aproximadamente 139 mil em 2009 ( $9^{\circ}$. lugar no estado), assim como a incidência de pobreza, que para o ano de 2003 ficou em 22,6\% (representando a estimativa do percentual de pessoas abaixo da linha de pobreza). Nos aspectos econômicos, o Sebrae/SC (2010) apresenta o produto interno bruto municipal (PIB-M), balança comercial, volume de empresas e empregos entre outros indicadores. 
Pontualmente sobre o PIB-M, a pesquisa do Sebrae/SC (2010) salienta que “(...) no comparativo da evolução deste indicador ao longo do período 2002-2006, o município apresentou um crescimento acumulado de 41,5\%, contra um aumento estadual de 67,2\%". Outro dado importante sobre o PIB-M de Jaraguá do Sul é sua estabilidade, no comparativo do ranking do estado, ficando com a $5^{\text {a }}$. posição de 2002 a 2005 e $6^{\text {a }}$. em 2006. Contribuindo com a análise do ranking do PIB-M, o Instituto Jourdan (2014) estende o horizonte de tempo para os anos de 1999 a 2012 e, assim como o Sebrae, percebe uma estabilidade na colocação de Jaraguá do Sul que, a exceção de 2006 (já mencionado) e 1999, mantém o 5. lugar nesses 13 anos.

De toda sorte, para Jaraguá do Sul, a apresentação de seus números e a análise da estabilidade observada no ranking do PIB-M do estado de Santa Catarina, esconde algo mais sutil que é, não apenas a comparação com seus vizinhos regionais, mas a evolução da sua estrutura produtiva e a íntima relação dessas características com as do próprio estado e as do Brasil, isso em termos ex-post. Já, com uma visão estratégica ou de futuro, é necessário entender também quais são as expectativas e os anseios dos empresários, em outras palavras, suas perspectivas de investimento no município. Nesse contexto, o objetivo deste trabalho é contribuir com os dois estudos já mencionados, apresentando e analisando os indicadores socioeconômicos do município de Jaraguá do Sul com destaque a evolução da estrutura produtiva vis-à-vis as características estaduais e nacionais, assim como levantar, a partir da perspectiva do empresariado do município, os fatores motivacionais de investimentos.

Para alcançar tais objetivos este trabalho está dividido em quadro seções incluindo esta introdução. A segunda seção é destinada a apresentação da base de dados e da metodologia a ser utilizada. De toda sorte, no compete à base de dados socioeconômicos, esta é composta por dados secundários de órgãos de pesquisa, sendo duas as funções desta coleta. A primeira está ligada à complementação da análise das pesquisas do Sebrae/SC (2010) e do Instituto Jourdan (2014), ambas já mencionadas. Já, a segunda, está intimamente ligada à proposta metodológica do trabalho, que é avaliar a correlação do perfil do sistema econômico do município com o do restante do estado e do Brasil, a partir de índices de correlação.

Por sua vez, a proposta metodológica tem como base o cálculo dos índices de correlação, como mencionado anteriormente, mais especificamente os de Pearson (valor) e de Spearman (posto/ordem). O foco do cálculo desses indicadores é medir a proximidade das características de Jaraguá do Sul com os demais municípios, sejam de Santa Catarina ou do restante do Brasil. Outra questão importante avaliada é o perfil do município consigo mesmo 
em períodos distintos, ou seja, avaliar se houve alteração na estrutura econômica com o passar do tempo. Ainda sobre a metodologia, destaca-se o uso da entrevista, mais especificamente a padronizada ou estruturada, realizada com um grupo de empresários. O foco deste método está no levantamento das expectativas desses empresários em relação aos planos de investimentos a serem realizados no município, ou como foi chamado, fatores motivadores de investimentos. Os resultados, tanto das correlações dos indicadores socioeconômicos quanto das entrevistas, serão analisados na terceira seção.

Por fim, na quarta e última seção, é apresentada as considerações finais, com as principais conclusões da pesquisa e sugestões para novas ações, destacando que o presente trabalho abre mais portas do que fecha, deixando à temática e, por que não dizer, a sua urgência, à espera de novas abordagens e tratamento.

\section{METODOLOGIA E APRESENTAÇÃO DOS DADOS}

Conjuntura econômica pode ser identificada como, de acordo com Sandroni (2005), o termo que define, deforma mais dinâmica do que "situação econômica", o fluxo e o refluxo das atividades de uma economia ou, de maneira mais genérica, o estudo da totalidade das condições de mercado, sendo a origem do conceito elaborado por volta do século XIX, a partir da periodicidade das crises. Ainda de acordo com o autor, o termo conjuntura pode também ser designado como o conjunto de fatores estritamente econômicos que influenciam na marcha da economia sendo esses fatores acompanhados a partir de indicadores de conjuntura como produção, estoques, número de pessoas empregadas, taxa de juros, receita e despesa do governo, taxa deformação de capital, renda nacional, índices de preço (inflação) entre outros, que se encontram em relações múltiplas e complexas, representadas por um conjunto sofisticado de dados.

Todas as análises da ciência econômica, como as do crescimento e desenvolvimento, processo de industrialização, comércio internacional e desempenho do mercado financeiro, em todas as esferas regionais (macro ou micro), demandam um volume considerável de dados. Esses dados, para serem transformados em informações, devem apresentar no mínimo duas características básicas: Periodicidade e Confiabilidade. Nesse sentido, é razoável dizer que não existe análise econômica sem dados, sejam eles puramente econômicos vinculados a contabilidade social/nacional ou, de forma específica, os socioeconômicos (índices de concentração e de desenvolvimento humano, indicadores de pobreza, mercado de trabalho, 
renda per capita e produto interno bruto, gasto público e etc) e econômico-financeiros (taxa de juros básica, mercado de capitais, taxas de câmbio, bolsa de valores, fluxo de capitais e etc). Em suma, é a rotina de busca e armazenamento desses dados econômicos (periódico e confiável) que dão alicerce a elaboração e análise de cenários econômicos (nacionais, estaduais e/ou municipais) de forma regular, auxiliando na tomada de decisões dos agentes econômicos.

Salienta-se que, para Meurer e Samohyl (2001), a tomada de decisões econômicas por empresas e indivíduos é parte inerente à vida, embora isto nem sempre seja percebido porque pode ser um processo intuitivo. Ainda de acordo com os autores, estas decisões são fortemente influenciadas por aquilo que está acontecendo ou virá a acontecer no ambiente econômico. Assim, em decorrência disso, o conhecimento sobre o que está acontecendo no ambiente mais amplo da economia do país e do mundo pode ter efeitos benéficos sobre as tomadas de decisão, tanto por reduzir as chances de erro como pela avaliação das consequências possíveis em diferentes situações.

Por uma perspectiva mais empresarial, conhecer o cenário e o ambiente de atuação das empresas é fundamental para subsidiar posicionamentos estratégicos. De acordo com o Sebrae (2012), só assim é possível identificar oportunidades de melhorias e de desenvolvimento de novas ações (produtos, processos, mercados e etc). Nesse sentido, o Sebrae passou a analisar dados de fontes como o IBGE, Bacen, IPEA, MTE, FGV, CNI, que divulgam, periodicamente, informações sobre importantes variáveis econômicas. Isto, para que a entidade possa lançar análises com objetivo de ajudar o empresário a tomar as decisões estratégicas no seu negócio. Já, na questão pública, pode-se citar a administração pública municipal, onde a conjuntura econômica,trabalho de pesquisa e editoração de dados, pode ser realizada por vários setores e entidades, que apresenta, deforma concisa, as potencialidades do município. Assim, a concretização desse trabalho é importante, pois constitui um poderoso instrumento de divulgação e atração de investimentos (Prefeitura..., 2014).

Seguindo essa linha, a análise para o município de Jaraguá do Sul será pautada em 03 grupos analíticos: 1) Características gerais; 2) Análise da evolução da estrutura produtiva; e 3 ) Levantamento dos fatores motivacionais de investimentos. No primeiro grupo será realizada essa análise retrospectiva, que não deve se confundir com um estudo de caráter histórico no seu sentido stricto. O objetivo é conhecer um pouco mais sobre Jaraguá do Sul/SC, assim, nesse tópico, uma revisão de sua trajetória. Para tanto, seguir-se-á a máxima de Max Weber de que “(...) nós economistas temos o hábito pedante, a que me agradaria permanecer fiel, de 
partir sempre do exame das condições externas do problema (...)”. Nesse sentido, deverá ser respondida a seguinte indagação: quais as características marcantes do desenvolvimento histórico-econômico do município vis-à-vis às mudanças no cenário brasileiro e, mesmo, mundial?

No intuito de criar uma organização metodológica ao trabalho, analisar-se-á, nessa etapa, os indicadores de população, desenvolvimento econômico, pobreza, comércio exterior e produção/renda. As informações pertinentes a esse primeiro grupo de análise serão coletadas, tabuladas e analisadas com o objetivo de produzir conhecimento a partir da conexão de dados antes dispersos nessas fontes. A base do método e a de Dados Secundários, ou seja, na utilização de informações já existentes em diversas fontes, neste caso no IBGE (Instituto Brasileiro de Geografia e Estatística), PNUD (Programa das Nações Unidas para o Desenvolvimento), FIRJAN (Federação das Indústrias do Estado do Rio de Janeiro), IPEA (Instituto de Pesquisa Econômica Aplicada), MIDC (Ministério do Desenvolvimento, Indústria e Comércio Exterior) entre outras bases.

A análise da evolução da estrutura produtiva ( $2^{\circ}$. grupo de análise), também utilizará dados secundários, agora os da RAIS (Relação Anual de Informações Sociais) do MTE (Ministério do Trabalho e Emprego), relacionadas ao emprego, remunerações e empresas, divididos conforme a CNAE (Classificação Nacional de Atividades Econômicas). A diferença deste grupo e do primeiro está na análise multivariada a ser realizada nesses dados. No caso específico do ferramental analítico, serão utilizados cálculos estatísticos a partir da correlação dos dados calculando os coeficientes de Pearson e de Spearman. O coeficiente de Pearson $\left(r_{p}\right)$ é descrito, segundo Lira e Chaves Neto (2006), como um indicador que analisa a interdependência entre duas variáveis. Já para Moore (2007, p. 100/101) “(...) o coeficiente de correlação de Pearson (r) é uma medida de associação linear entre variáveis”. De acordo com Filho (2009), o coeficiente de Pearson varia de -1 a 1, onde, o sinal indica a direção do relacionamento e o valor demonstra a força da relação entre as variáveis, portanto, ainda segundo o autor, uma correlação perfeita (-1 ou 1) “(...) indica que o escore de uma variável pode ser determinado exatamente ao se saber o escore da outra”. Sendo assim, uma correlação de valor zero indicará o contrário, ou seja, que não existe relação linear entre as variáveis.

Para se classificar qualitativamente, será utilizada a escala de Callegari Jacques (2003, p. 90), onde: se $0,0<\left|r_{p}\right|<0,3$, observa-se fraca correlação linear; se $0,3 \leq\left|r_{p}\right|<0,6$, observa-se moderada correlação linear; se $0,6 \leq\left|r_{p}\right|<0,9$, observa-se forte correlação linear; se $0,9 \leq\left|r_{p}\right|<1,0$, observa-se correlação linear muito forte. Com isso, quanto mais perto de 
1, independente do sinal, maior é o grau de correlação entre as variáveis e quanto mais perto de zero, menor é a força da mesma.

Já, o coeficiente de Spearman $\left(\mathrm{r}_{\mathrm{s}}\right)$, se baseia no ordenamento e é, segundo Siegel e Castellan Jr. (2006, p. 266), uma medida de associação entre duas variáveis onde é necessário que as mesmas sejam medidas sobretudo em uma escala ordinal, formando-se assim duas séries em ordem. Sendo assim, se verifica a possibilidade de duas hipóteses: i) Hipótese $\mathrm{H}_{0}$, onde não há interligação entre as variáveis em questão e ii) Hipótese $\mathrm{H}_{1}$, em que se observa essa interligação. O teste de hipótese será feito a partir do teste t de Student, comparando o t calculado (equação 1) com o t crítico (com n-2 graus de liberdade e nível de significância de $1 \%)$,

$$
t=r_{s} \sqrt{\frac{n-2}{1-r_{s}^{a}}} \sim t_{n-2}
$$

onde: $t$ é a estatística do teste (t calculado); $r_{s}$ é o Coeficiênte de Correlação de Spearman; e $n$ representa a amostra.

Ainda em relação ao coeficiente de correlação de Spearman, segundo Pontes (2010), este nada mais é que o coeficiente de correlação linear de Pearson aplicado aos postos dos dados, obtidos independentemente para cada variável. Diferente do coeficiente de Pearson, onde para que ele seja igual a 1 ou -1 , a variável $\mathrm{Y}$ deve ser função linear da variável $\mathrm{X}$, os valores 1 ou -1 para o coeficiente de correlação de Spearman são fáceis de acontecerem na prática.

Por fim, o terceiro grupo de análise está relacionado ao levantamento das expectativas do empresariado de Jaraguá do Sul/SC. Essa ação tem por objetivo determinar os fatores motivadores de investimentos no município, para tanto será realizada uma entrevista do tipo estruturada junto aos empresários. Destaca-se a importância da entrevista como uma técnica de coleta de dados e sua utilização para a captação de dados subjetivos (BONI e QUARESMA, 2005). Como observado por Boni e Quaresma (2005), Marcone e Lakatos (2003) e Mattos (2005) as entrevistas estruturadas são elaboradas mediante questionário totalmente estruturado, ou seja, é aquela onde as perguntas são previamente formuladas/padronizadas e tem-se o cuidado de não fugir a elas. O motivo da padronização é obter, dos entrevistados, respostas às mesmas perguntas, permitindo "(...) que todas elas sejam comparadas com o mesmo conjunto de perguntas, e que as diferenças devem refletir diferenças entreos respondentes e não diferenças nas perguntas" (LODI apud, MARCONE e 
LAKATOS, 2003, p. 197). De toda sorte, duas questões são importantes para a elaboração do roteiro/questões: preparação da entrevista e diretrizes da entrevista. Na preparação específica (organizar roteiro ou formulário), as questões importantes a serem observadas são:

1. Jaraguá do Sul é base de grandes empresas que mantém interesses em diversas regiões do país e mesmo no exterior. Considerando uma linha de tempo, em que momento a sua empresa passou a focar seu crescimento fora do município?

2. Considerando o volume investido como o elemento viabilizador da estratégia em aproximadamente quanto tempo os investimentos fora do município superaram os já realizados em Jaraguá do Sul?

3. Quais foram às condições (estruturais, de aspectos da economia doméstica ou de expectativas de atuação externa) consideradas mais propícias para esta estratégia de expansão fora de Jaraguá do Sul?

4. Os investimentos fora de Jaraguá do Sul foram feitos em que locais? Hoje o foco de investimentos continua sendo a mesma região ou outra?

5. Hoje qual é o montante de investimentos que sua empresa nas plantas de Jaraguá do Sul?

6. Este investimento nas unidades do município, certamente se realizou ao longo do tempo, mas houve algum período que mereça destaque? Por que motivo?

7. No momento a empresa pretende realizar investimentos em unidades fora de Jaraguá do Sul (no exterior e em território nacional)? E em Jaraguá do Sul?

Uma vez manipulados os dados e obtidos os resultados, o passo seguinte é a análise e interpretação dos mesmos, constituindo-se ambas no núcleo central da próxima seção. Destaca-se que análise (ou explicação) é a tentativa de evidenciar as relações existentes entre os fenômenos estudados e outros fatores. Essas relações podem ser "estabelecidas em função de suas propriedades relacionais de causa-feito, produtor-produto, de correlações, de análise de conteúdo etc" (TRUJILLO, apud, MARCONE e LAKATOS, 2003, p. 168). Já a Interpretação refere-se a atividade intelectual que procura dar um significado mais amplo às respostas, vinculando-as a outros conhecimentos. Em geral, a interpretação significa a exposição do verdadeiro significado do material apresentado, em relação aos objetivos propostos e ao tema. 


\section{ANÁLISE E INTERPRETAÇÃO DOS RESULTADOS}

\section{Características gerais de Jaraguá do Sul}

No começo da década de 90, uma nova transformação iniciaria no país. Deste modo passou-se a perceber a importância dos atuais parques tecnológicos para o desenvolvimento industrial e, portanto, para o crescimento diferenciado das regiões, sendo estas valorizadas pela presença de centros de ensino e pesquisa, oferta de trabalho profissional qualificado, relações industriais articuladas geograficamente, facilidade de acesso, base educacional e cultural, clima de negócios, concentração dos recursos de pesquisa entre outros. Tais condições criam o ambiente propício para a ocorrência do que se pode chamar de "Desenvolvimento Poligonal”, o que de acordo com Diniz (1993) corresponde a uma situação “(...) onde um número limitado de novos pólos de crescimento ou regiões tem capturado a maior parte das novas atividades econômicas". Conforme apresentado na Figura 1, Jaraguá do Sul está inserida nessa região, representando também um pólo de crescimento à época.

\section{Figura 1 - Zona Espacial atingida pelo "Novo Polígono de Aglomeração Industrial" a partir da década de 1990}
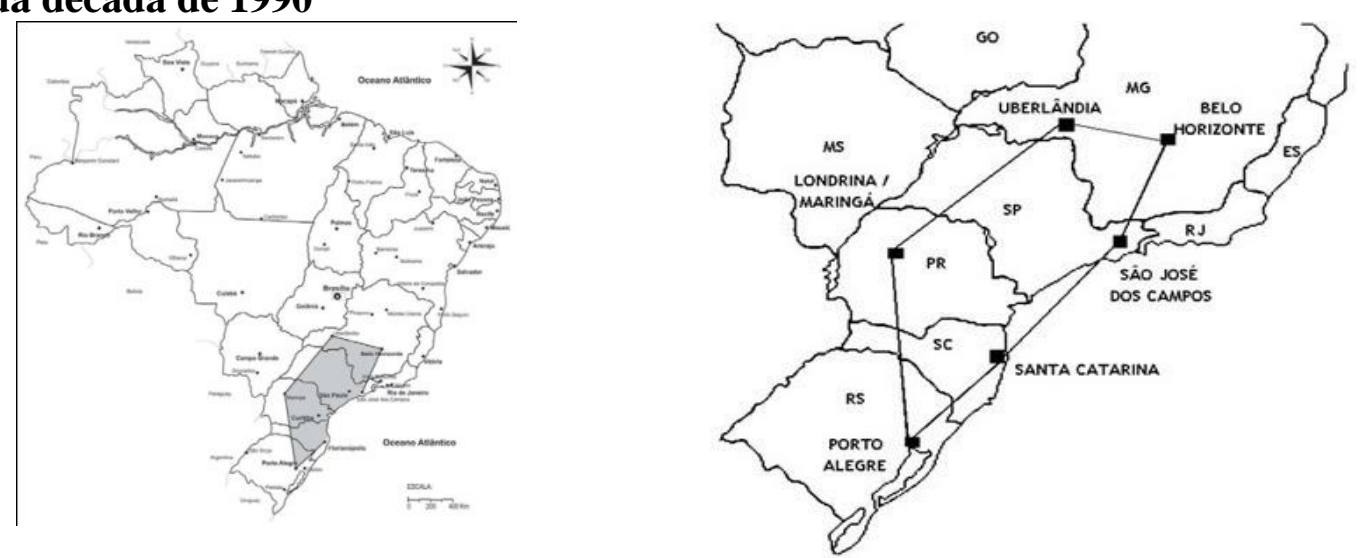

Fonte: elaborado pelos autores com base em Diniz (1993, p. 36).

Entre os fatores marcantes dessa fase para o município está à própria evolução do número de seus habitantes. Em 1992 Jaraguá do Sul apresentava, de acordo com dados do IBGE (2015a), uma população aproximada de 79 mil pessoas, número esse que mais que dobra em 2014 (algo em torno de 160 mil). Mais interessante é a trajetória do crescimento se comparado com os demais municípios de Santa Catarina e os do Brasil. Conforme destacado no Gráfico 1 é possível visualizar, no ano de 1997, o descolamento e consequente afastamento 
da trajetória do município em relação ao restante dos demais municípios do estado e do Brasil, esses dois últimos mantendo uma relação muito próxima. Enquanto Jaraguá do Sul aumentava sua população residente em mais de $100 \%$, os valores estaduais e nacionais não atingiram $50 \%$ de aumento.

Ainda olhando a questão da população, a partir da Tabela 1, percebe-se a transição entre campo e cidade. De acordo com os dados do IBGE (2015a), em 1970 dos 30 mil habitantes do município, $51 \%$ tinham domicílio na área rural, situação que se inverte na década de 1980 e se intensifica nos anos de 1990, chegado em 2010 com apenas 7\% da população na zona rural. É importante perceber que o próprio processo de industrialização contribui para a migração observada, assim como esse fato contribuiu com a deterioração das condições de vida nos centros urbanos, questão que só poderá ser respondida para Jaraguá do Sul com base nos índices de desenvolvimento humano e pobreza, tratados a diante.

\section{Gráfico 1 - Índice de crescimento populacional de Jaraguá do Sul, Restantes de Santa Catarina e Brasil para os anos de 1992 a 2014 (1992=100)}

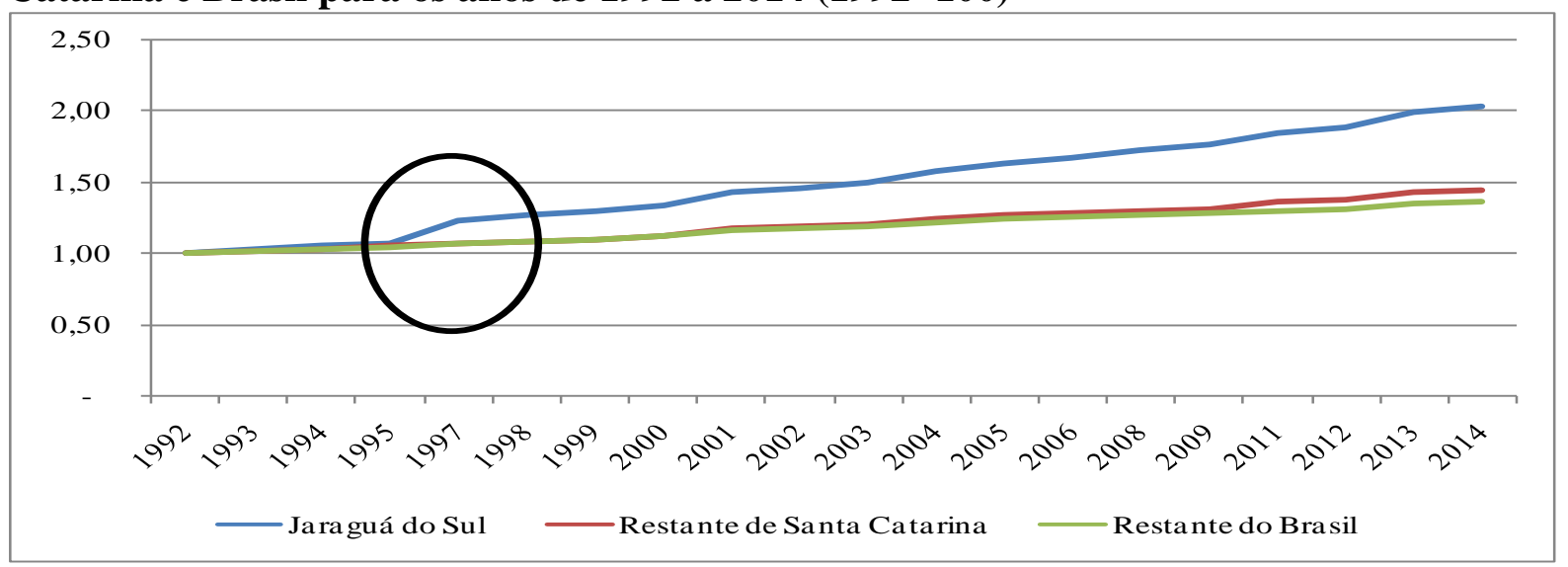

Fonte: elaborado pelos autores com base em IBGE (2015a).

Outra forma de análise da população é por meio da estrutura etária e da distribuição por sexo. No caso da estrutura etária, esta serve de base para a razão de dependência (percentual da população de menos de 15 anos e de 65 anos ou mais) e para a taxa de envelhecimento (razão entre a população de 65 anos ou mais e a total), ambos medem a fragilidade em relação à População Economicamente Ativa (PEA). Sobre os indicadores o PNUD (2015) destaca que, “(...) entre 2000 e 2010, a razão de dependência no município passou de $44,31 \%$ para $35,2 \%$ e a taxa de envelhecimento, de 4,4\% para 5,15\%". Outro fato interessante desse período (pós anos de 1990) é a evolução da qualidade de vida dos habitantes de Jaraguá do Sul. Como mencionado pode-se utilizar três indicadores para 
mensurar esse quesito: IDH-M, IFDM e o de incidência de pobreza. O primeiro, mais tradicional, contudo de periodicidade mais longa para municípios (a cada 10 anos), apresenta o desempenho de Jaraguá do Sul em três períodos distintos (1991, 2000 e 2010).

A partir dos dados apresentados pelo PNUD (2015) é possível fazer duas inferências, ainda seguindo a questão da evolução municipal a partir dos anos de 1990. A primeira, e mais trivial, diz respeito à capacidade do município manter o indicador de desenvolvimento humano a frente dos observados no estado de Santa Catarina e do Brasil, assim como sua evolução, passando de índice classificado como médio em 1991, alto em 2000 e posteriormente, em 2010, para muito alto - de acordo com o ranking apresentado pelo PNUD. Por sua vez, a segunda, está relacionada ao crescimento percentual desse índice. Entre os anos de 1991 e 2010, Jaraguá do Sul teve um aumento de aproximadamente 33\% em seu indicador, frente $43 \%$ do estado e $48 \%$ no do Brasil. Esse resultado indica que o aumento do índice de desenvolvimento humano estaria relacionado com rendimentos decrescentes, demandando esforços cada vez maiores para a melhora do indicador.

Tabela 1 - População residente por situação do domicílio de 1970 a 2010

\begin{tabular}{|c|c|c|c|c|c|c|c|c|c|c|}
\hline & 1970 & & 1980 & & 1991 & & 2000 & & 2010 & \\
\hline Urbana & 14747 & $49 \%$ & 32297 & $67 \%$ & 62565 & $81 \%$ & 96320 & $89 \%$ & 132800 & $93 \%$ \\
\hline Rural & 15499 & $51 \%$ & 16241 & $33 \%$ & 14403 & $19 \%$ & 12169 & $11 \%$ & 10323 & $7 \%$ \\
\hline Total & 30246 & & 48538 & & 76968 & & 108489 & & 143123 & \\
\hline
\end{tabular}

Fonte: elaborado pelos autores com base em IBGE (2015a).

Ainda sobre o IDH-M, de acordo com o PNUD (2015), “(...) no município, a dimensão cujo índice mais cresceu,entre 1991 e 2010, em termos absolutos foi Educação (com crescimento de 0,351), seguida por Longevidade e por Renda".No comparativo entre Jaraguá do Sul e Joinville, é possível perceber uma similaridade entre os dois municípios, com ligeira vantagem de Joinville no ano de 2010 , vantagem esta pautada no quesito Renda (0,793 para Jaraguá do Sul e 0,795 para Joinville), mas principalmente no índice Longevidade ( 0,865 para Jaraguá do Sul e 0,889 para Joinville).É importante salientar que, a dimensão Longevidade considera apenas a esperança de vida ao nascere a Renda do IDHM considera apenas a renda per capita da população, sendo a limitação deste último não considerar a desigualdade de renda entre os habitantes (a exemplo do Índice de Gini).

Por outro lado, o IFDM da Firjan, “(...) criado para tentar suprir a inexistência de um parâmetro para medir periodicamente o desenvolvimento socioeconômico dos municípios brasileiros (...)" (GAZETADOPOVO, 2008), medido a partir de 2005 (Tabela 2), retrata o 
desenvolvimento humano com base em três áreas de atuação (Emprego \& renda, Educação e Saúde-a maior diferença em relação ao IDH-M está na avaliação da variável emprego) e é classificado em: municípios com IFDM entre 0 e 0,4 - baixo estágio de desenvolvimento; municípios com IFDM entre 0,4 e 0,6 - desenvolvimento regular; municípios com IFDM entre 0,6 e 0,8 - desenvolvimento moderado; e municípios com IFDM entre 0,8 e 1,0 - alto estágio de desenvolvimento (FIRJAN, 2015).Destaca-se que além da periodicidade, a base de dados entre o IDH-M e o IFDM também diferem.

Contudo, a despeito do debate metodológico, olhando apenas para o município de Jaraguá do Sul, percebe-se uma melhora do indicador nos anos de 2005 a 2007, saindo de 0,7838 para 0,8255 no índice global (IFDM). Esse resultado fez com que o município saísse da $147^{\mathrm{a}}$. posição para a $51^{\mathrm{a}}$. no ranking nacional. Já, no tocante ao estado, sua posição em 2005 era a $14^{\text {a }}$. subindo para a $5^{\text {a }}$. posição em 2007. A partir de 2008 observa-se uma inflexão na trajetória, com o recuo do índice em 0,39\% em 2008 e 1,1\% em 2009, ambos em comparação a 2007. Entre os fatores determinantes para tal declínio está o componente Emprego \& renda, saindo da classificação de alto estágio de desenvolvimento (entre 0,8 e 1,0 ) para desenvolvimento moderado (entre 0,6 e 0,8) em 2009 e 2011. Mesmo classificado entre 0,8 e 1,0, no índice Emprego \& renda, o ano de 2010 teve seu valor no limite inferior dessa classificação $(0,8033)$, denotando a dificuldade observada a partir de 2009 . Retornando ao índice global, a recuperação vista em 2010 não foi suficiente para melhorar a posição do município no ranking tanto nacional quanto estadual (ver Tabela 1).

A situação de Jaraguá do Sul no IFDM, principalmente em relação a seu retrocesso no ranking, denotaria uma piora nas condições socioeconômicas como a mencionada pelo estudo do Sebrae/SC (2010). De acordo com a entidade, como já apresentado na introdução deste trabalho, no ano de 2003 o município apresentou uma estimativa do percentual de pessoas abaixo da linha de pobreza na ordem de 22,6\% (incidência de pobreza). Contudo, este valor deve representar um caso isolado, pois, com base nos dados do Atlas do Desenvolvimento Humano no Brasil (2015), entre 2000 e 2010 os indicadores de Demografia, Educação, Habitação, Renda e Vulnerabilidade tiveram uma melhora quase que na totalidade de seus valores, mantendo índices melhores que os observados no estado e no país. Em linhas gerais destaca-se, como exemplo, a redução da mortalidade infantil (reduziu de 17,42\% para $10,21 \%$ entre 2000 e 2010) e o aumento da probabilidade de sobrevivência até 60 anos (84,76\% para 85,68\% no mesmo período) no caso da Demografia, têm-se também o aumento do número de domicílios com banheiro e água encanada, coleta de lixo e acesso a energia 
elétrica, assim como o aumento da porcentagem de pessoas nas escolas e o grau de escolaridade. Já, em relação à Renda e Vulnerabilidade, destacam-se os dados das Tabelas 3 e 4.

Tabela 2 - Índice Firjan de Desenvolvimento Municipal - IFMD (2005 a 2011)

\begin{tabular}{ccccccc}
\hline & $\begin{array}{c}\text { Ranking } \\
\text { Nacional }\end{array}$ & $\begin{array}{c}\text { IFDM Geral } \\
\text { Estadual }\end{array}$ & IFDM & $\begin{array}{c}\text { Emprego \& } \\
\text { Renda }\end{array}$ & Educação & Saúde \\
\hline $\mathbf{2 0 0 5}$ & $147^{\circ}$ & $14^{\circ}$ & 0,7838 & 0,7080 & 0,8103 & 0,8331 \\
$\mathbf{2 0 0 6}$ & $52^{\circ}$ & $5^{\circ}$ & 0,8250 & 0,8491 & 0,7878 & 0,8382 \\
$\mathbf{2 0 0 7}$ & $51^{\circ}$ & $5^{\circ}$ & 0,8251 & 0,8324 & 0,8019 & 0,8409 \\
$\mathbf{2 0 0 8}$ & $75^{\circ}$ & $6^{\circ}$ & 0,8219 & 0,8302 & 0,8054 & 0,8301 \\
$\mathbf{2 0 0 9}$ & $118^{\circ}$ & $12^{\circ}$ & 0,8160 & 0,7732 & 0,8496 & 0,8251 \\
$\mathbf{2 0 1 0}$ & $143^{\circ}$ & $14^{\circ}$ & 0,8292 & 0,8033 & 0,8568 & 0,8276 \\
$\mathbf{2 0 1 1}$ & $137^{\circ}$ & $18^{\circ}$ & 0,8347 & 0,7773 & 0,8821 & 0,8446 \\
\hline
\end{tabular}

Fonte: elaborado pelos autores com base em FIRJAN (2015).

Sobre a Tabela 3 destaca-se a redução da porcentagem de vulneráveis a pobreza entre 2000 e 2010. Com base nos dados do Atlas, esse percentual saiu de 15,48\% da população em 200 para 4,12\% em 2010. Desta forma, é possível inferir que, a despeito das diferenças metodologias utilizadas pelo indicador apresentado pelo Sebrae/SC (incidência de pobreza) e pelo da Atlas (vulneráveis à pobreza), este fato foi superado durante a primeira década dos anos 2000. Outro fato importante é a redução dos índices de concentração entre 2000 e 2010, melhora observada em ambos os indicadores (Gini e Theil-L). Esse resultado é potencializado se considerado a estabilidade/rigidez dos índices nos períodos anteriores (1991 e 2000). Por fim, os dados da Tabela 3 contribuem com os resultados apresentados na Tabela 4 sobre os indicadores de vulnerabilidade.

De forma mais pontual sobre a Tabela 4 destaca-se a redução da mortalidade infantil. Esse indicador é importante pois, conforme o IBGE (2015c), a redução da mortalidade está intimamente relacionada ao “(...) papel da melhoria das práticas sanitárias e inovações tecnológicas e do desenvolvimento socioeconômico (...)". Vale salientar que o instituto frisa que os fatores de desenvolvimento socioeconômico são "determinantes" para a sua redução, dessa demonstrando a intima relação da questão econômica com os aspectos de vulnerabilidade. Outro indicador apresentado na Tabela 4 é a Razão de Dependência, que também apresentou redução durante o período analisado. Esse índice, de acordo com IBGE (2015b), é o “(...) peso da população considerada inativa (0 a 14 anos e 65 anos e mais de idade) sobre a população potencialmente ativa (15 a 64 anos de idade) (...)", e tem relação direta com a oferta de mão de obra. 
Tabela 3 - Indicadores de Renda (1991, 2000 e 2010)

\begin{tabular}{|c|c|c|c|}
\hline & 1991 & 2000 & 2010 \\
\hline \multicolumn{4}{|c|}{ Índice de Theil - L } \\
\hline Brasil & 0,78 & 0,76 & 0,68 \\
\hline Santa Catarina & 0,54 & 0,56 & 0,42 \\
\hline Jaraguá do Sul (SC) & 0,38 & 0,39 & 0,31 \\
\hline \multicolumn{4}{|c|}{ Índice de Gini } \\
\hline Brasil & 0,63 & 0,64 & 0,60 \\
\hline Santa Catarina & 0,55 & 0,56 & 0,49 \\
\hline Jaraguá do Sul (SC) & 0,47 & 0,48 & 0,42 \\
\hline \multicolumn{4}{|c|}{ \% de vulneráveis à pobreza } \\
\hline$\overline{\text { Brasil }}$ & 58,53 & 48,39 & 32,56 \\
\hline Santa Catarina & 49,34 & 31,40 & 12,36 \\
\hline Jaraguá do Sul (SC) & 21,60 & 15,48 & 4,12 \\
\hline
\end{tabular}

Fonte: Atlas do Desenvolvimento Humano no Brasil (2015).

Tabela 4 - Indicadores de Vulnerabilidade (1991, 2000 e 2010).

\begin{tabular}{lccc}
\hline & $\mathbf{1 9 9 1}$ & $\mathbf{2 0 0 0}$ & $\mathbf{2 0 1 0}$ \\
\hline Brasil & & Mortalidade infantil & 16,70 \\
Santa Catarina & 44,68 & 30,57 & 11,54 \\
Jaraguá do Sul (SC) & 24,84 & 16,79 & 10,21 \\
\hline & 23,08 & 17,42 & 45,92 \\
\hline Brasil & & Razão de dependência & 40,34 \\
Santa Catarina & 65,43 & 54,94 & 35,15 \\
\hline Jaraguá do Sul (SC) & 59,91 & 50,52 & 44,31 \\
\hline
\end{tabular}

Fonte: Atlas do Desenvolvimento Humano no Brasil (2015).

Contudo, mesmo com a melhora dos indicadores no período de 2000 a 2010, conforme dados do Atlas do Desenvolvimento Humano no Brasil (2015), é inegável (até mesmo pela análise do senso comum) que o período compreendido entre 2008 e 2011 tenham sido difíceis para a economia de Jaraguá do Sul. Essa constatação esta ligada ao perfil do sistema produtivo do município que tem intima relação com o comércio exterior, o que ficou claro pela apresentação do Sebrae/SC (2010, p. 36-39), tanto pelo montante negociado quanto pela listagem de empresas exportadores. A dificuldade mencionada esta ligada a crise financeira de 2008 e a crise da dívida pública européia em 2011.

Ainda nesse sentido, observa-se que o período posterior a setembro de 2008 é marcado pela retração, não apenas no fluxo de comércio exterior (exportação e importação), mas também na própria atividade industrial. Em Jaraguá do Sul as exportações e importações seguem a mesma tendência observada no aspecto macroeconômico, com dois pontos de inflexão representados pelas duas crises (conforme apontado no Gráfico 6). 
Gráfico 6 - Exportações e Importações de Jaraguá do Sul de 2006-2014 (US\$ Milhões F.O.B.)

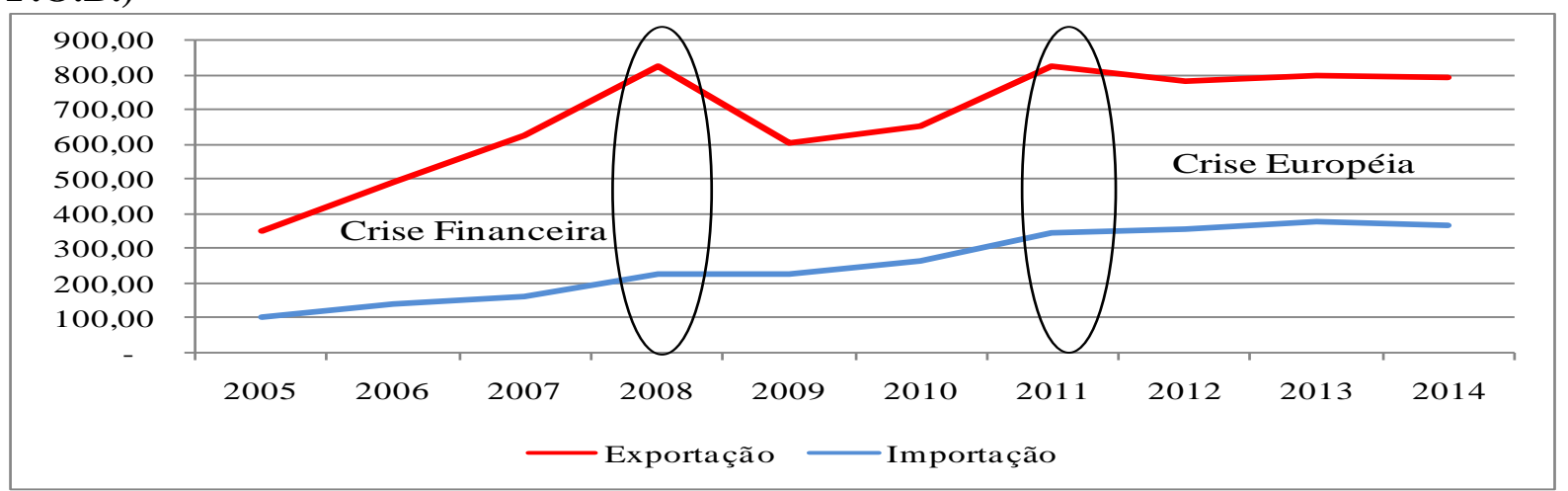

Fonte: MDIC (2015).

Contudo, diferente do país, que teve em 2008, 13,5\% das suas exportações pautadas em bens de capital, 18,95\% de bens de consumo, 9,33\% de combustíveis e lubrificantes, $55,78 \%$ de matérias-primas e produtos intermediários,no município, para o mesmo período a participação de bens de capital era de aproximadamente $89 \%$, seguido de $7,5 \%$ de bens de consumo e 3,56\% de bens intermediários. Ou seja, a pauta de exportação do município apresenta uma maior participação de bens de alto valor agregado, desta forma a redução deste mercado tem impactos maiores no tocante à renda local.

Por outro lado, ainda comparando os dados dos Gráficos 5 e 6, as importações tiveram uma redução mais suavizada no município em relação aos dados nacionais. A partir dos dados do MDIC (2015), houve uma retração de 14\% entre 2008 e 2009 na importação de bens de capital (essa conta representa mais de 40\% das importações, chegando a 57,76\% em 2008), contudo com aumento de $40 \%$ na importação de bens intermediários, indicando uma retração no investimento proveniente de poupança externa, contudo com expansão na produção dado o aumento na aquisição de matéria-prima importada.

Mantendo o tema do comércio exterior destaca-se os principais países destino das exportações de Jaraguá do Sul. Ao analisar a lista dos dez maiores clientes do município (Tabela 5) percebe-se que esse grupo de países responde por aproximadamente 2/3 no ano de 2014, com destaque os Estados Unidos da América, que em dez anos passou de uma participação de 19,8\% em 2005 para 26,9\% em 2014, no período pós crise financeira (2009) essa participação chegou a $17,4 \%$. Outra questão interessante é a regularidade dos países membros deste grupo - entre 2005 e 2014, Cuba e Itália deram lugar a Emirados Árabes Unidos e Chile, sendo mantidos os demais oito países. No tocante aos produtos ressalta-se a participação dos "Motores e geradores, elétricos, exceto os grupos electrogéneos" com mais 
de 75,6\% da pauta de exportação no ano de 2014, sendo essa uma tendência observada nos anos anteriores também.

Tabela 5 - Dez principais países de destino das exportações de Jaraguá do Sul e suas respectivas participações (2005 e 2014)

\begin{tabular}{|c|c|c|c|c|c|}
\hline & \multicolumn{2}{|l|}{2005} & & \multicolumn{2}{|l|}{2014} \\
\hline & US\$ & $\%$ & & US\$ & $\%$ \\
\hline ESTADOS UNIDOS & 69.699 .732 & 19,82 & ESTADOS UNIDOS & $213.111 .084,00$ & 26,86 \\
\hline ARGENTINA & 31.025 .782 & 8,82 & ALEMANHA & $59.821 .803,00$ & 7,54 \\
\hline AFRICA DO SUL & 27.690 .116 & 7,88 & AFRICA DO SUL & $55.482 .503,00$ & 6,99 \\
\hline MEXICO & 22.164 .679 & 6,30 & ARGENTINA & $51.113 .248,00$ & 6,44 \\
\hline ALEMANHA & 17.991 .340 & 5,12 & EMIRADOS ÁRABES UNIDOS & $40.306 .708,00$ & 5,08 \\
\hline CANADÁ & 15.698 .532 & 4,46 & CANADÁ & $31.761 .833,00$ & 4,00 \\
\hline REINO UNIDO & 15.354 .266 & 4,37 & REINO UNIDO & 28.734.609,00 & 3,62 \\
\hline BELGICA & 11.027.979 & 3,14 & BELGICA & $26.650 .625,00$ & 3,36 \\
\hline ITALIA & 9.997 .092 & 2,84 & MEXICO & $25.473 .882,00$ & 3,21 \\
\hline \multirow[t]{2}{*}{ CUBA } & 7.235 .416 & 2,06 & CHILE & $19.878 .859,00$ & 2,51 \\
\hline & $.651 .523,00$ & 62,75 & & $552.337 .168,00$ & 69,61 \\
\hline
\end{tabular}

Fonte: MDIC (2015).

Por fim, o último conjunto de dados a ser analisado é o relacionado ao Produto Interno Bruto Municipal (PIB-M). Sobre ele cita-se o estudo do Instituto Jourdan (2014) que tem como base uma análise dos valores corretes do PIB-M dos municípios do estado de Santa Catarina e o conseqüente ranking e comparativo. Em relação ao ranking, o instituto apresenta a evolução do município entre os anos de 1999 e 2012, onde o mesmo demonstra uma estabilidade na $5^{\text {a }}$. posição, exclusive nos anos de 2006 e 1999 (início da série). Nesse quesito vale destacar que dado a situação das relações internacionais (demonstradas anteriormente) era de se esperar uma deterioração da posição em 2009, contudo o mesmo não foi observado, mostrando que essa crise pode ter atingido os demais municípios do limite superior desse ranking também. A partir da evolução do índice de crescimento do PIB-M real ou a preço constante (este deflacionado de acordo com o IPCA), conforme Gráfico 7, tem-se claro que o ano de 2006 representou uma inflexão na trajetória ascendente do PIB-M, assim como em 2009, todavia mais intensa. 
Gráfico 7 - Índice de crescimento do PIB de Jaraguá do Sul deflacionados com base no IPCA $(1999$ a $2010-1999=100)$

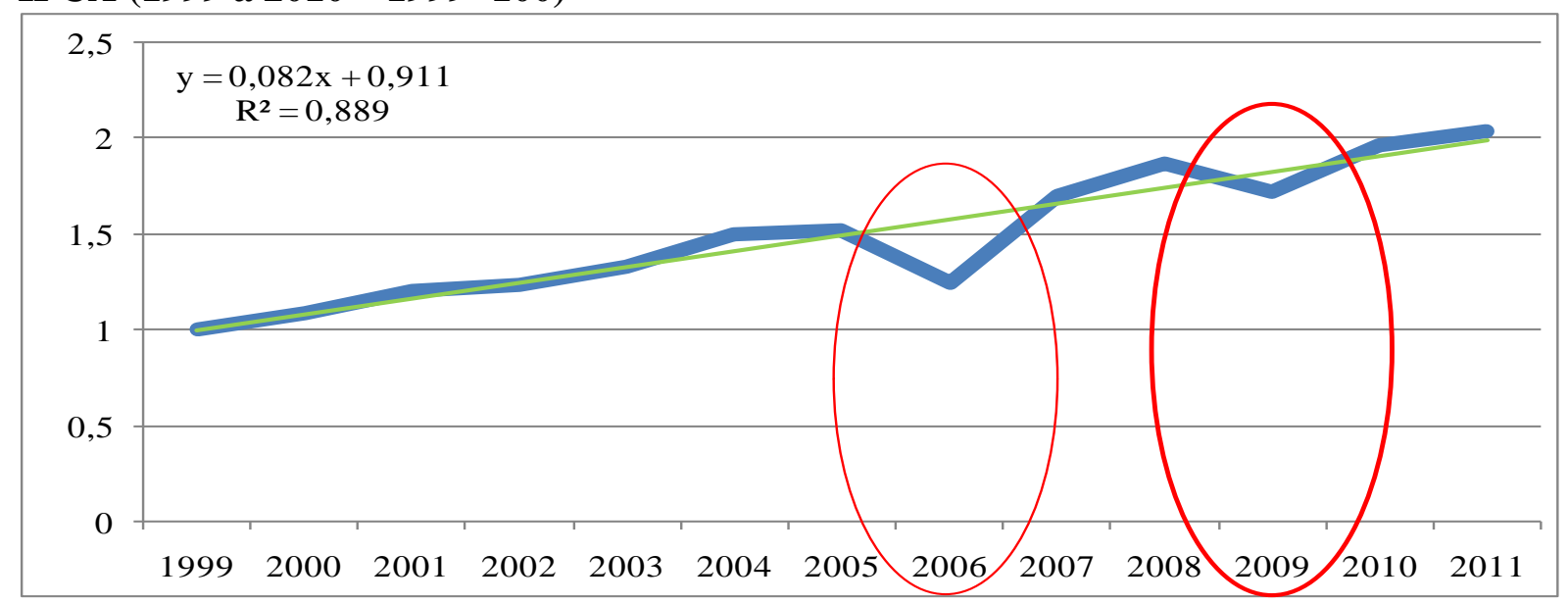

Fonte: elaborado pelos autores com base no IBGE (2015a).

O valor observado em 2006 não pode ser explicado com base nos dados do comércio exterior, assim deve ser um fato particular do município não compartilhado na mesma intensidade com os demais municípios do estado. Outra questão importante sobre o estudo do instituto e a comparação dos resultados de Jaraguá do Sul com os de Joinville e Itajaí. Mesmo sendo um município aparentemente com as mesmas características de Jaguará do Sul, Joinville apresente uma característica que por si só diminui a similaridade entre os dois que é a infra-estrutura logística, com saída direta para a BR-101 (duplicada).

No caso de Itajaí, além de uma logística facilitada, o município e base portuária, o que também o descola dos demais municípios, basta perceber que o avanço de posições de Itajaí tem correlação positiva com o aumento do fluxo do comércio internacional, principalmente commodities nos últimos anos, características apresentadas por outros municípios de outros estados como Paranaguá no Paraná. Na mesma linha é importante perceber a importância dos acontecimentos observados em 2006 e 2008 para o posicionamento do município frente a sua região (micro e meso) e ao estado. De acordo com a Tabela 6 é possível ilustrar essa situação, onde o município de Jaraguá do Sul tem reduções consideráveis nas participações, em 2006 a participação do município era em média 80\% do valor de 1999.

Ainda em relação aos impactos de 2006, percebe-se que estes foram mais expressivos no setor industrial, pois esse período representa o único ano em que o setor serviços teve uma participação superior ao da indústria, conforme apresentado na Tabela 7. Outra informação na tabela é a redução da participação do setor agropecuário na atividade econômica do município, fato esperado conforme evolução da população apresentada anteriormente na Tabela 1, sobre a migração campo cidade. Fato interessante é a inflexão positiva da atividade 
agropecuária a partir das dificuldades de 2006, mais precisamente em 2007 (questão sinalada no Gráfico 8).

Tabela 6 - Participação do valor adicionado bruto a preços correntes total de Jaraguá do Sul em relação a Microrregião, Mesorregião e Unidade da Federação (1999 e 2011)

\begin{tabular}{|c|c|c|c|c|c|c|c|c|c|c|c|c|c|}
\hline & 1999 & 2000 & 2001 & 2002 & 2003 & 2004 & 2005 & 2006 & 2007 & 2008 & 2009 & 2010 & 2011 \\
\hline Microrregião geográfica (\%) & 20,64 & 21,07 & 21,44 & 20,77 & 21,03 & 22,53 & 21,55 & 16,48 & 21,03 & 21,54 & 20,51 & 19,42 & 19,60 \\
\hline Mesorregião geográfica (\%) & 15,87 & 16,05 & 16,42 & 15,70 & 15,84 & 16,88 & 16,76 & 13,06 & 16,74 & 16,97 & 16,12 & 15,64 & 15,86 \\
\hline Unidade da federação (\%) & 3,59 & 3,66 & 3,76 & 3,68 & 3,73 & 4,01 & 4,02 & 3,15 & 4,05 & 3,97 & 3,67 & 3,79 & 3,78 \\
\hline Microrregião geográfica (Base 1999=1) & 1,00 & 1,02 & 1,04 & 1,01 & 1,02 & 1,09 & 1,04 & 0,80 & 1,02 & 1,04 & 0,99 & 0,94 & 0,95 \\
\hline Mesorregião geográfica (Base 1999=1) & 1,00 & 1,01 & 1,03 & 0,99 & 1,00 & 1,06 & 1,06 & 0,82 & 1,05 & 1,07 & 1,02 & 0,99 & 1,00 \\
\hline Unidade da federação (Base 1999=1) & 1,00 & 1,02 & 1,05 & 1,03 & 1,04 & 1,12 & 1,12 & 0,88 & 1,13 & 1,11 & 1,02 & 1,06 & 1,05 \\
\hline
\end{tabular}

Fonte: elaborado pelos autores com base no IBGE(2015a).

Tabela 7 - Participação dos setores no PIB Municipal (valor adicionado - preços básicos) de Jaraguá do Sul -2000 a 2010

\begin{tabular}{lccccccccccc}
\hline & $\mathbf{2 0 0 0}$ & $\mathbf{2 0 0 1}$ & $\mathbf{2 0 0 2}$ & $\mathbf{2 0 0 3}$ & $\mathbf{2 0 0 4}$ & $\mathbf{2 0 0 5}$ & $\mathbf{2 0 0 6}$ & $\mathbf{2 0 0 7}$ & $\mathbf{2 0 0 8}$ & $\mathbf{2 0 0 9}$ & $\mathbf{2 0 1 0}$ \\
\hline Agropecuária & $1,1 \%$ & $1,0 \%$ & $1,1 \%$ & $1,2 \%$ & $0,9 \%$ & $0,8 \%$ & $1,0 \%$ & $0,5 \%$ & $0,6 \%$ & $0,7 \%$ & $0,7 \%$ \\
Indústria & $55,9 \%$ & $54,4 \%$ & $50,9 \%$ & $52,2 \%$ & $55,9 \%$ & $52,5 \%$ & $42,9 \%$ & $52,7 \%$ & $56,5 \%$ & $54,8 \%$ & $53,8 \%$ \\
Serviços & $43,0 \%$ & $44,6 \%$ & $48,0 \%$ & $46,6 \%$ & $43,2 \%$ & $46,7 \%$ & $56,2 \%$ & $46,8 \%$ & $43,0 \%$ & $44,5 \%$ & $45,5 \%$ \\
\hline
\end{tabular}

Fonte: elaborado pelos autores com base no IBGE (2015a).

De toda sorte, os dados apresentados nessa subseção indicas fatos novos não observados anteriormente, a exemplo do confronto dos índices de desenvolvimento humano, os impactos das crises internacionais sobre o desempenho econômico do município, assim como as oscilações negativas no PIB-M, principalmente em 2006 (fato novo). 
Gráfico 8 - Índice de crescimento do PIB de Jaraguá do Sul dividido por setor de atividade $(\mathbf{2 0 0 0}=\mathbf{1 0 0})$

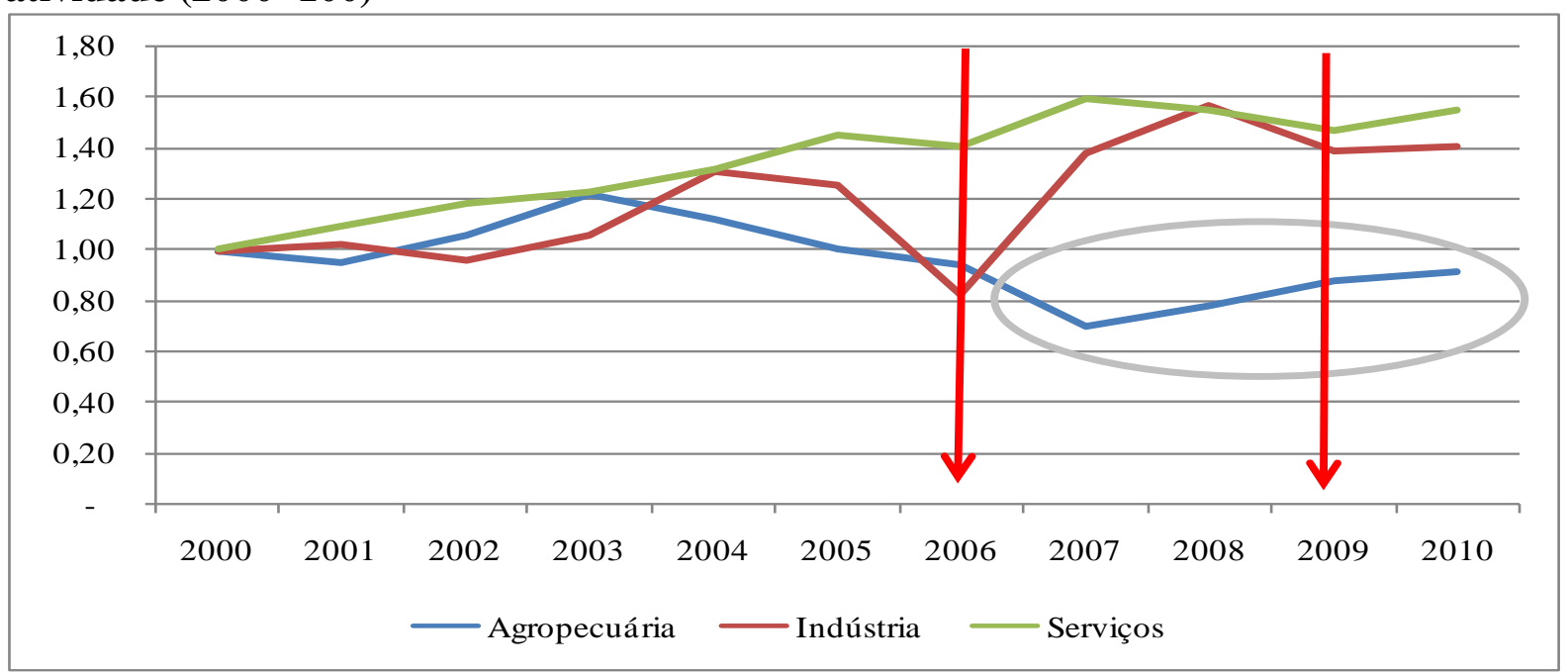

Fonte: elaborado pelos autores com base no $\operatorname{IBGE(2015a).~}$

Nesse contexto a próxima subseção tem objeto a profundas essas discussões a partir de outra base de dados, a da Relação Anual de Informações Sociais - RAIS (MTE, 2015), relacionando emprego, rendimentos e empresas em outro método o de análise de correlação, tudo com o objetivo de perceber o perfil e evolução da estrutura produtiva de Jaraguá do Sul.

\section{PERFIL E EVOLUÇÃO DA ESTRUTURA PRODUTIVA}

A análise do perfil e evolução da estrutura produtiva de Jaraguá do Sul será elaborada a partir dos dados do Ministério do Trabalho e Emprego (MTE, 2015) divididos em estabelecimentos (empresas), empregos e remunerações (média mensal de salários mínimos pagos no total do setor), para o intervalo de 11 anos (2003 a 2013), divididos em 59 setores conforme divisão do Cadastro Nacional de Atividades Econômicas (CNAE 95 - ver Anexo 7). Além da análise da evolução do próprio município, este será comparado com outros quadro municípios (Blumenau, Florianópolis, Itajaí e Joinville), seguindo a lista dos principais municípios apresentados pelo Instituto Jourdan (2014), e com o próprio estado de Santa Catarina. De toda sorte, antes da análise propriamente dita, é importante observar o panorama geral de Jaraguá do Sul, o que pode ser visto a partir do resumo das estatísticas do Cadastro Central de Empresas (Tabela 8) e da apresentação dos 10 (dez) principais setores em número de estabelecimentos/empresas, empregos e remunerações no ano de 2013 (Tabela 9).

Entre as informações importantes na Tabela 8 destaca-se o efeito da crise financeira de 2008 sobre o total de pessoas ocupadas e as assalariadas no ano subsequente (2009), onde 
observa-se uma redução de aproximadamente $0,8 \%$ no número de total de pessoas ocupadas (comparado o ano de 2008), por sua vez o de pessoas assalariadas tem uma variação de $1,35 \%$ para o mesmo período. Outro aspecto que vale a explicação é a redução sistemática do salário médio mensal, medido em salários mínimos, a qual deve ser relativizada. Esta relativização está ligada aos ganhos reais do salário mínimo (acima da inflação), entre outras palavras, 3 (três) salários mínimos de 2012 valem mais que 3 (salários mínimos de 2006).

Tabela 8 - Resumo das estatísticas do Cadastro Central de Empresas (2006-2012)

\begin{tabular}{|c|c|c|c|c|c|c|c|}
\hline & 2012 & 2011 & 2010 & 2009 & 2008 & 2007 & 2006 \\
\hline Número de unidades locais & 7.591 & 7.452 & 7.393 & 7.144 & 7.085 & 6.730 & 6.324 \\
\hline Pessoal ocupado total & 78.808 & 78.786 & 77.280 & 73.106 & 73.690 & 70.341 & 64.064 \\
\hline Pessoal ocupado assalariado & 69.524 & 69.692 & 68.080 & 64.145 & 65.021 & 61.616 & 55.984 \\
\hline Salários e outras remunerações (Mil Reais) & 1.840 .832 & 1.643 .670 & 1.454 .435 & 1.261 .303 & 1.182 .188 & 1.032 .133 & 916.531 \\
\hline Salário médio mensal (Salários mínimos) & 3,2 & 3,3 & 3,2 & 3,3 & 3,4 & 3,5 & 3,7 \\
\hline Número de empresas atuantes & 7.290 & 7.168 & 7.105 & 6.860 & 6.795 & - & - \\
\hline
\end{tabular}

Fonte: elaborado pelos autores com base no IBGE (2015a).

Já, em relação aos principais setores de Jaraguá do Sul em 2013 (Tabela 9), destaca-se o fato que independente do dado analisado os dez maiores setores (cada um em sua categoria) representam mais de $70 \%$ do observado no total do município, seja para estabelecimentos, empregos ou remunerações. Outra questão importante, no caso específico de emprego e remunerações, é a importância dos setores de Confecção de Artigos do Vestuário e Acessórios e o de Fabricação de Máquinas, Aparelhos e Materiais Elétricos, que aparecem entre os três principais setores, representando 30\% dos empregos (algo em torno de 24\% da PEA de 2010) e $28 \%$ das remunerações. 
Tabela 9 - Dez maiores setores no ano de 2013

\begin{tabular}{|c|c|c|}
\hline Em número de Estabelecimentos/Empresas & Valor & Participação \\
\hline COMÉRCIO VAREJISTA E REPARAÇÃO DE OBJETOS PESSOAIS E DOMÉSTICOS & 1.242 & $26 \%$ \\
\hline SERVIÇOS PRESTADOS PRINCIPALMENTE ÀS EMPRESAS & 363 & $7 \%$ \\
\hline COMÉRCIO E REPARAÇÃO DE VEÍCULOS AUTOMOTORES E MOTOCICLETAS & 320 & $7 \%$ \\
\hline CONSTRUÇÃO & 297 & $6 \%$ \\
\hline SAÚDE E SERVIÇOS SOCIAIS & 261 & $5 \%$ \\
\hline ALOJAMENTO E ALIMENTAÇ̃̃̃O & 259 & $5 \%$ \\
\hline CONFECÇÃO DE ARTIGOS DO VESTUÁRIO E ACESSÓRIOS & 247 & $5 \%$ \\
\hline COMÉRCIO VAREJISTA E REPARAÇÃO DE OBJETOS PESSOAIS E DOMÉSTICOS & 225 & $5 \%$ \\
\hline ATIVIDADES IMOBILIÁRIAS & 203 & $4 \%$ \\
\hline TRANSPORTE TERRESTRE & 157 & $3 \%$ \\
\hline Subtotal & 3.574 & $73 \%$ \\
\hline Total & 4.864 & $100 \%$ \\
\hline Em número de Empregos & Valor & Participação \\
\hline CONFECÇÃO DE ARTIGOS DO VESTUÁRIO E ACESSÓRIOS & 11.427 & $16 \%$ \\
\hline FABRICAÇÃO DE MÁQUINAS, APARELHOS E MATERIAIS ELÉTRICOS & 9.838 & $14 \%$ \\
\hline COMÉRCIO VAREJISTA E REPARAÇÃO DE OBJETOS PESSOAIS E DOMÉSTICOS & 6.742 & $9 \%$ \\
\hline SERVIÇOS PRESTADOS PRINCIPALMENTE ÀS EMPRESAS & 5.980 & $8 \%$ \\
\hline FABRICAÇÃO DE PRODUTOS TÊXTEIS & 4.703 & $7 \%$ \\
\hline ADMINISTRAÇÃO PÚBLICA, DEFESA E SEGURIDADE SOCIAL & 3.870 & $5 \%$ \\
\hline FABRICAÇÃO DE MÁQUINAS E EQUIPAMENTOS & 3.142 & $4 \%$ \\
\hline FABRICAÇÃO DE EQUIPAMENTOS DE INSTRUMENTAÇÃO MÉDICOHOSPITALARES & 2.468 & $3 \%$ \\
\hline FABRICAÇÃO DE PRODUTOS ALIMENTÍCIOS E BEBIDAS & 2.196 & $3 \%$ \\
\hline COMÉRCIO E REPARAÇÃO DE VEÍCULOS AUTOMOTORES E MOTOCICLETAS & 2.155 & $3 \%$ \\
\hline Subtotal & 52.521 & $73 \%$ \\
\hline Total & 72.023 & $100 \%$ \\
\hline Em volume de Remunerações & Valor & Participação \\
\hline SERVIÇOS PRESTADOS PRINCIPALMENTE ÀS EMPRESAS & $31.805,11$ & $15 \%$ \\
\hline CONFECÇÃO DE ARTIGOS DO VESTUÁRIO E ACESSÓRIOS & $30.774,09$ & $14 \%$ \\
\hline FABRICAÇÃO DE MÁQUINAS, APARELHOS E MATERIAIS ELÉTRICOS & $29.820,85$ & $14 \%$ \\
\hline ADMINISTRAÇÃO PÚBLICA, DEFESA E SEGURIDADE SOCIAL & $19.819,86$ & $9 \%$ \\
\hline COMÉRCIO VAREJISTA E REPARAÇÃO DE OBJETOS PESSOAIS E DOMÉSTICOS & $13.870,37$ & $6 \%$ \\
\hline FABRICAÇÃO DE PRODUTOS TÊXTEIS & $11.664,27$ & $5 \%$ \\
\hline FABRICAÇÃO DE MÁQUINAS E EQUIPAMENTOS & $10.949,52$ & $5 \%$ \\
\hline FABRICAÇÃO DE PRODUTOS ALIMENTÍCIOS E BEBIDAS & $7.408,39$ & $3 \%$ \\
\hline FABRICAÇÃO DE EQUIPAMENTOS DE INSTRUMENTAÇÃO MÉDICOHOSPITALARES & $6.654,34$ & $3 \%$ \\
\hline COMÉRCIO E REPARAÇÃO DE VEÍCULOS AUTOMOTORES E MOTOCICLETAS & $5.708,29$ & $3 \%$ \\
\hline Subtotal & $168.475,09$ & $77 \%$ \\
\hline Total & $218.542,84$ & $100 \%$ \\
\hline
\end{tabular}

Total

218.542,84

Fonte: elaborado pelos autores com base no MTE (2015).

Caracterizado o município, o próximo passo é entender as diferenças entre Jaraguá do Sul e outros municípios relevantes no estado de Santa Catarina. Essa análise foi elaborada a partir das mesmas informações apresentadas anteriormente (estabelecimentos, empresas e remunerações) em um período de 11 anos (2003 a 2013), com base nos índices de correlação de Pearson (valor) e Spearman (posto/ordem). A primeira análise (Tabela 10) indica uma similaridade entre as localidades comparadas com Jaraguá do Sul no quesito número de estabelecimentos, principalmente no índice de Pearson.

Neste índice observa-se uma correlação muito forte, ou seja, a distribuição das empresas entre os setores é parecida. Contudo, quando analisado a ordem dos maiores setores (índice de Spearman), ainda no número de estabelecimentos, Jaraguá do Sul se aproxima mais de Blumenau e Joinville. Como já mencionado, Itajaí tem características particulares como cidade portuária, assim como, Florianópolis como cidade turística - dificultando a comparação entre esses dois municípios com Jaraguá do Sul. 
Tabela 10 - Índice de correlação (Pearson e Spearman) entre Jaraguá do Sul e Blumenau, Florianópolis, Itajaí, Joinville e Santa Catarina para o número de estabelecimentos/empresas (2003 a 2013)

\begin{tabular}{lrrrrr}
\hline & Blumenau & Florianópolis & Itajaí & Joinville & Santa Catarina \\
\hline Pearson Correlation &, $986^{* *}$ &, $908^{* *}$ &, $953^{* *}$ &, $985^{* *}$ &, $984^{* *}$ \\
Sig. (2-tailed) &, 000 &, 000 &, 000 &, 000 &, 000 \\
N & 649 & 649 & 649 & 649 & 649 \\
\hline Spearman's rho Correlation Coefficient &, $963^{* *}$ &, $818^{* *}$ &, $874^{* *}$ &, $966^{* *}$ &, $940^{* *}$ \\
Sig. (2-tailed) &, 000 &, 000 &, 000 &, 000 &, 000 \\
N & 649 & 649 & 649 & 649 & 649 \\
\hline **. Correlation
\end{tabular}

**. Correlation is significant at the 0.01 level (2-tailed).

Fonte: elaborado pelos autores com base no MTE (2015).

As diferenças observadas a partir da análise dos maiores setores em número de estabelecimentos (índice de Spearman) são evidenciadas com base na comparação das localidades no tocante ao número de empregos por setor (Tabela 11). Nesse sentido, na distribuição dos empregos pelos setores, o município que mais se aproxima do perfil de Jaraguá do Sul foi Blumenau, que apresentou um índice de correlação de Pearson de 0,687 (classificado como forte correlação).

Tabela 11 - Índice de correlação (Pearson e Spearman) entre Jaraguá do Sul e Blumenau, Florianópolis, Itajaí, Joinville e Santa Catarina para o número de empregos (2003 a 2013)

\begin{tabular}{lrrrrr}
\hline & Blumenau & Florianópolis & Itajaí & Joinville & Santa Catarina \\
\hline Pearson Correlation &, $687^{* *}$ &, $241^{* *}$ &, $454^{* * *}$ &, $458^{* * *}$ &, $585^{* * *}$ \\
Sig. (2-tailed) &, 000 &, 000 &, 000 &, 000 &, 000 \\
$\mathrm{~N}$ & 649 & 649 & 649 & 649 & 649 \\
\hline Spearman's rho Correlation Coefficient &, $891^{* *}$ &, $592^{* *}$ &, $722^{* *}$ &, $866^{* *}$ &, $887^{* * *}$ \\
Sig. (2-tailed) &, 000 &, 000 &, 000 &, 000 &, 000 \\
$\mathrm{~N}$ & 649 & 649 & 649 & 649 & 649 \\
\hline$* *$ Correlation is significant at the 0.01 level (2-tailed) & & & &
\end{tabular}

Fonte: elaborado pelos autores com base no MTE (2015).

Destaca-se que essa comparação, assim como as demais, não discute se a posição de Jaraguá do Sul é melhor ou pior que a dos municípios comparados, apenas se as características da estrutura produtiva do município se aproximam ou divergem das demais localidades. Continuando a análise, o índice de Spearman para empregos, vai na mesma linha discutida até aqui, que a proximidade entre Blumenau e Joinville com Jaraguá do Sul, no quesito principais setores empregadores.

Por fim, a comparação com as remunerações por setor entre os municípios, converge com o que já foi visualizado. Contudo, a correlação entre os setores diminuem, onde a melhor 
classificação foi a correlação moderada, abaixo de 0,6 (Blumenau - 0,59), mas mantendo a tendência de proximidade entre Blumenau e Joinville com Jaraguá do Sul.

Tabela 12 - Índice de correlação (Pearson e Spearman) entre Jaraguá do Sul e Blumenau, Florianópolis, Itajaí, Joinville e Santa Catarina para as remunerações (2003 a 2013)

\begin{tabular}{lrrrrr}
\hline & Blumenau & Florianópolis & Itajaí & Joinville & Santa Catarina \\
\hline Pearson Correlation &, $590^{* *}$ &, $261^{* *}$ &, $423^{* *}$ &, $352^{* *}$ &, $478^{* *}$ \\
Sig. (2-tailed) &, 000 &, 000 &, 000 &, 000 &, 000 \\
$\mathrm{~N}$ & 649 & 649 & 649 & 649 & 649 \\
\hline Spearman's rho Correlation Coefficient &, $865^{* *}$ &, $565^{* *}$ &, $647^{* *}$ &, $842^{* *}$ &, $872^{* *}$ \\
Sig. (2-tailed) &, 000 &, 000 &, 000 &, 000 &, 000 \\
$\mathrm{~N}$ & 649 & 649 & 649 & 649 & 649 \\
\hline$* *$ Correlation is significant at the 0.01 level (2-tailed). & & & & \\
Fonte: elaborado pelos autores com base no MTE (2015). & & & &
\end{tabular}

Os dados apresentados nas Tabelas 10,11 e 12 contribuem para a discussão sobre o cuidado na comparação de Jaraguá do Sul com outras localidades, seja por meio dos indicadores socioeconômicos ou a partir das estratégias particulares de desenvolvimento local. De qualquer forma, outra maneira de avaliar o município é a partir das mutações na sua estrutura produtiva (estabelecimentos, empregos e remunerações), isso foi elaborado com base na comparação dos valores de 2003 a 2013. É importante salientar que as mudanças estruturais são lentas e em alguns casos levam décadas (a exemplo da implementação e plena utilização de uma nova tecnologia). Assim, é reconhecido a priori que as alterações no período analisado serão sutis, essas mudanças estão ilustradas nos Gráficos 9, 10 e 11.

Ao analisar a evolução do município durante os anos de 2003 a 2013 percebe-se, com base nos gráficos anteriores que a mudança em Jaraguá do Sul é lenta, contudo mantém uma trajetória de afastamento do seu perfil do início da série (2003). Outra forma de observar essa mudança é a partir da variação do número de estabelecimentos, empregos e remunerações, conforme apresentado na Tabela 13. Destaca-se que dos 59 setores analisados, o município não manteve atividade, durante os 11 anos analisados, em sete setores, são eles: Extração de Carvão Mineral; Extração de Petróleo e Serviços Relacionados; Extração de Minerais Metálicos; Fabricação de Produtos do Fumo; Transporte Aquaviário; Transporte Aéreo; e Organismos Internacionais e Outras Instituições Extraterritoriais. Desses setores, muitos o município não apresenta vocação básica para o seu desenvolvimento, contudo vale ressaltar a importância do transporte aéreo como uma das bases para o sistema logístico de uma localidade industrial, como a de Jaraguá do Sul que mantém intima ligação não apenas com o 
restante do país, mas com o mundo, a sua ausência já denota uma desvantagem estratégica, a exemplo de Joinville.

Gráfico 9 - Evolução dos índices de correlação (Pearson e Spearman) do número de estabelecimentos de Jaraguá do Sul a partir de 2003

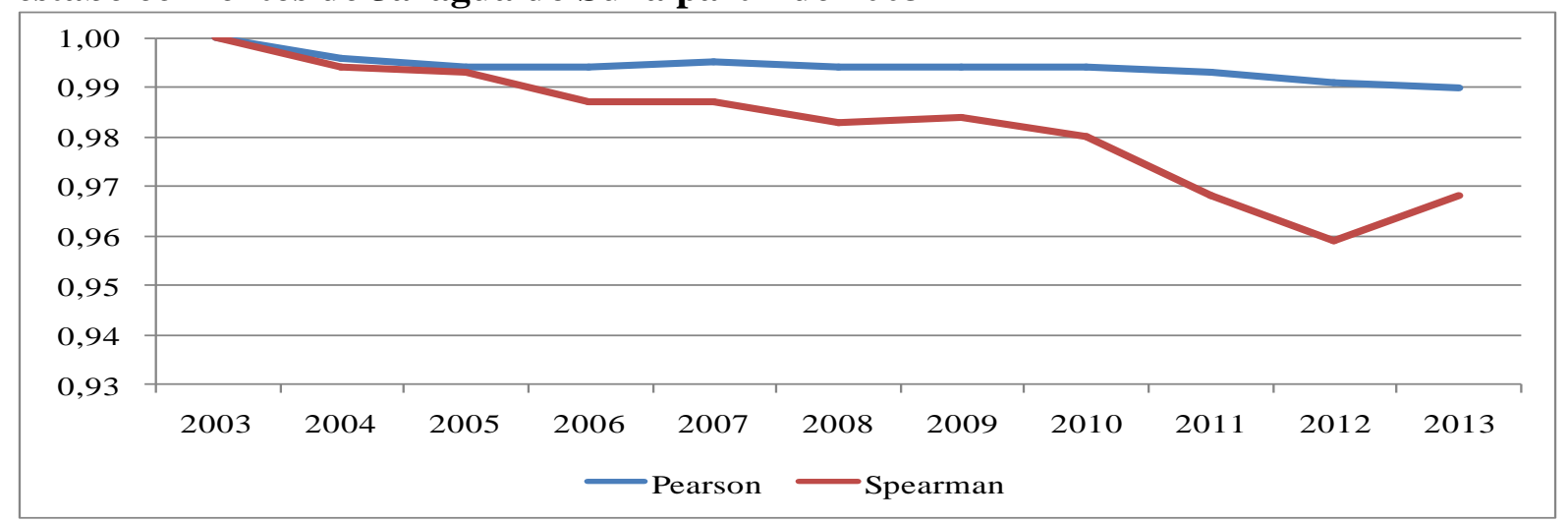

Fonte: elaborado pelos autores com base no MTE (2015).

Gráfico 10 - Evolução dos índices de correlação (Pearson e Spearman) do número de empregos de Jaraguá do Sul a partir de 2003

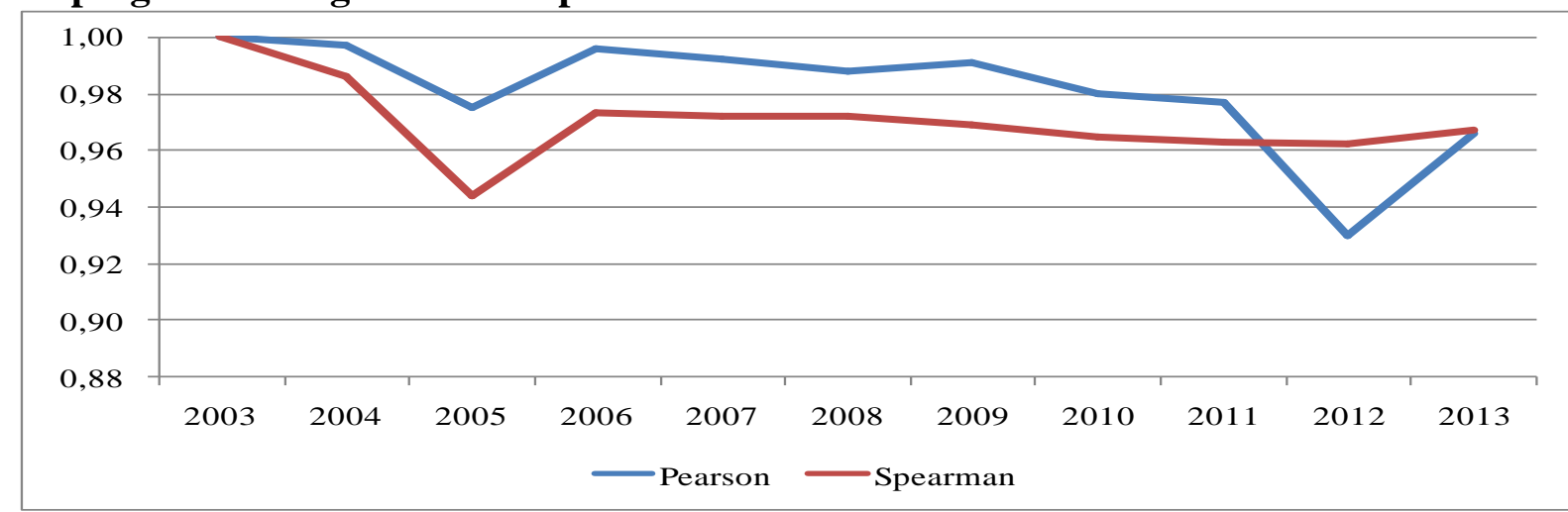

Fonte: elaborado pelos autores com base no MTE (2015).

Gráfico 11 - Evolução dos índices de correlação (Pearson e Spearman) das remunerações de Jaraguá do Sul a partir de 2003

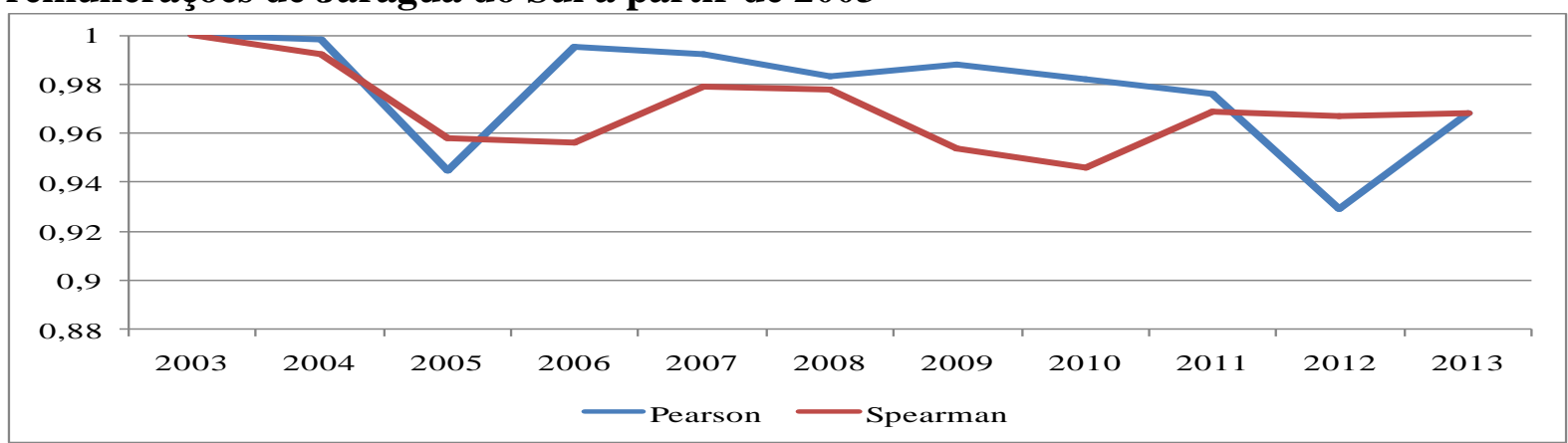

Fonte: elaborado pelos autores com base no MTE (2015).

Ao olhar a Tabela 13 percebe-se as alterações vividas pelo município, entre elas o crescimento do setor de confecções, que aumentou em $24,7 \%$ o número de estabelecimentos 
com conseqüente acréscimo de empregos e remunerações e na outra ponta o encolhimento do setor de fabricação de produtos alimentícios e bebidas que apresentou uma evolução de $-4,9 \%$ no número de estabelecimentos, $-37,8 \%$ em empregos e $-39,3 \%$ nas remunerações, assim como setores que aumentaram em número de estabelecimentos mas reduziram os empregos e/ou remunerações, como fabricação de produtos de metal exceto máquinas e equipamentos e o de educação (este último com aumento em 77,8\% no número de estabelecimentos teve uma redução de $11,7 \%$ nas remunerações).

Outra questão importante sobre os setores que não se destacaram no município, e ligado com o de Educação, é o desempenho do setor de Pesquisa e Desenvolvimento. Este é composto por atividades ligadas com Pesquisa e desenvolvimento experimental em ciências físicas e naturais e Pesquisa e desenvolvimento experimental em ciências sociais e humanas e compõem juntamente com outras atividades (como a de Serviços Prestados Principalmente às Empresas) a área de Atividades Profissionais, Científicas e Técnicas. Esse setor apresentou 1 (um) estabelecimento ativo em 2005, com 9 empregos e 30,12 salários mínimos de remuneração mensal (algo em torno de 3,34 salários mínimos mensais por emprego). Como é possível perceber a sua importância não está em sua relevância econômica para Jaraguá do Sul, mas assim como o transporte aéreo, consiste em uma base de serviços para o desenvolvimento tecnológico do parque industrial do município. Vale salientar que já em 2006 esse setor tem suas atividades encerradas não apresentando nenhuma nova empresa até o ano de 2013.

Tabela 13 - Principais setores de Jaraguá do Sul (ponderado estabelecimento, emprego e remunerações) em 2003 e evolução entre 2003 e 2013

\begin{tabular}{|c|c|c|c|c|c|c|}
\hline & \multicolumn{3}{|c|}{ Dados de 2003} & \multicolumn{3}{|c|}{ Evolução de 2003 a 2013} \\
\hline & Estabelecimentos & Empregos & Remuneração & Estabelecimentos & Empregos & Remuneração \\
\hline 1 Confecção de Artigos do Vestuário e Acessórios & 198 & 7847 & $28.068,21$ & $24,7 \%$ & $45,6 \%$ & $9,6 \%$ \\
\hline 2 Comércio Varejista e Reparação de Objetos Pessoais & 781 & 3718 & $9.584,73$ & $59,0 \%$ & $81,3 \%$ & $44,7 \%$ \\
\hline 3 Fabricação de Máquinas, Aparelhos e Materiais Elétricos & 19 & 6881 & $28.399,34$ & $68,4 \%$ & $43,0 \%$ & $5,0 \%$ \\
\hline 4 Serviços Prestados Principalmente Às Empresas & 279 & 3561 & $21.840,04$ & $30,1 \%$ & $67,9 \%$ & $45,6 \%$ \\
\hline 5 Fabricação de Produtos Alimentícios e Bebidas & 81 & 3529 & $12.213,60$ & $-4,9 \%$ & $-37,8 \%$ & $-39,3 \%$ \\
\hline 6 Administração Pública, Defesa e Seguridade Social & 3 & 2375 & $15.215,13$ & $100,0 \%$ & $62,9 \%$ & $30,3 \%$ \\
\hline 7 Fabricação de Produtos Têxteis & 59 & 2742 & $8.597,49$ & $57,6 \%$ & $71,5 \%$ & $35,7 \%$ \\
\hline 8 Comércio e Reparação de Veículos Automotores e Motocicletas & 221 & 1164 & $3.297,75$ & $44,8 \%$ & $85,1 \%$ & $73,1 \%$ \\
\hline 9 Saúde e Serviços Sociais & 169 & 902 & $3.223,38$ & $54,4 \%$ & $114,1 \%$ & $67,0 \%$ \\
\hline 10 Comércio por Atacado e Representantes Comerciais & 135 & 999 & $4.080,65$ & $66,7 \%$ & $73,3 \%$ & $22,2 \%$ \\
\hline 11 Alojamento e Alimentação & 157 & 925 & $1.809,25$ & $65,0 \%$ & $86,6 \%$ & $71,8 \%$ \\
\hline 12 Transporte Terrestre & 114 & 1043 & $3.198,96$ & $37,7 \%$ & $66,0 \%$ & $44,9 \%$ \\
\hline 13 Construção & 122 & 826 & $2.122,23$ & $143,4 \%$ & $141,5 \%$ & $67,1 \%$ \\
\hline 14 Fabricação de Máquinas e Equipamentos & 57 & 1016 & $4.155,10$ & $100,0 \%$ & $209,3 \%$ & $163,5 \%$ \\
\hline 15 Educação & 45 & 969 & $4.955,05$ & $77,8 \%$ & $54,4 \%$ & $-11,7 \%$ \\
\hline 16 Fabricação de Produtos de Metal Exceto Máquinas e Equipamentos & 94 & 770 & $2.229,72$ & $3,2 \%$ & $-18,2 \%$ & $-27,0 \%$ \\
\hline 17 Atividades Associativas & 75 & 567 & $1.902,36$ & $26,7 \%$ & $59,1 \%$ & $19,6 \%$ \\
\hline 18 Fabricação de Artigos de Borracha e Plástico & 35 & 786 & $2.198,75$ & $37,1 \%$ & $75,3 \%$ & $56,2 \%$ \\
\hline 19 Atividades Imobiliárias & 92 & 263 & 587,77 & $120,7 \%$ & $207,6 \%$ & $187,2 \%$ \\
\hline 20 Fabricação de Móveis e Indústrias Diversas & 48 & 605 & $1.651,97$ & $27,1 \%$ & $15,5 \%$ & $-1,8 \%$ \\
\hline
\end{tabular}

Fonte: elaborado pelos autores com base no MTE (2015). 
É importante perceber que esta discussão sobre as ligações da cadeia produtiva (a exemplificadas pelas questões de logística e serviços de pesquisa) envolvem duas consequências. A primeira é a fuga de investimentos, que buscam localidades com uma melhor oferta de insumos e serviços. E, a segunda, é a fuga ou exportação de renda, a partir da contração de serviços especializados ou compra de insumos fora do município. De toda sorte, essa discussão diz respeito aos ligamentos e a análise da cadeia produtiva, o que pode ser observada com base na elaboração da matriz insumo-produto municipal. Mas para qualificar o cenário apresentado pela análise estatística dos indicadores socioeconômicos e da evolução do sistema produtivo, na próxima subseção será avaliado a perspectiva do empresariado.

\section{FATORES MOTIVADORES DE INVESTIMENTOS}

Inicialmente nos cabe informar que o tópico que segue foi elaborado com base em entrevistas estruturadas, realizadas com executivos de algumas empresas do município, elencadas pela Associação Empresarial de Jaraguá do Sul. É também importante alertar que as citadas entrevistas foram agendadas pela Associação Empresarial sem a interferência do pesquisador de campo. As entrevistas evidenciam que as empresas de Jaraguá do Sul, seguiram o caminho tradicional ou usual de internacionalização das empresas brasileiras. Iniciaram o processo por via de exportações, na sequência estabeleceram estruturas de comercialização nos países destino de seus produtos, incluindo, criação de Centros de Distribuição e de assistência técnica (nos casos específicos em que tal serviço se fazia vital), para somente após a certa consolidação do mercado alvo, iniciar processo de investimento externo.

Claro está que tal processo de internacionalização de investimentos não se deu de forma homogênea ou linear, nem ao mesmo em ritmos e amplitudes iguais, porém os inquiridos alertam de forma uníssona a inflexão e desaceleração de tal processo após a chamada crise subprime dado a deterioração das condições internacionais de crédito e a contração das economias principalmente de Europa e Norte-américa, representado por um ambiente de incerteza. Tal fenômeno somente agora começa a ser revertido. Independente dos aspectos acima, as empresas de Jaraguá do Sul mantiveram sua base tecnológica centrada no município, ou seja, na prática o processo de internacionalização, como conhecido na literatura, jamais foi concluído, pois a base de geração de valor na maior dos casos analisados, 
por opção, permaneceu no município. Esse processo pode ser observado pelo tipo de investimento, pautado principalmente em base tecnológica de alto valor agregado.

As entrevistas também são reveladoras sobre a migração de investimentos no território nacional. As empresas consultadas informam que os investimentos realizados no Brasil dizem respeito a busca de elevação de competitividade potencial, ou seja, de vantagens de custo de insumos, vantagens tributárias e mesmo de mão-de-obra que elevem os resultados ex-ante. Destaque-se que os citados investimentos deslocam-se da planta para a cadeia, o que equivale a uma opção estratégica de manter nas plantas industriais locais a maior parcela dos investimentos e utilizar suas unidades em outros estados como fornecedoras de estágios (normalmente básicos) da produção. Nesse sentido, pode-se citar também a busca por patamares menores em suas curvas de aprendizagem, onde a instalação de plantas em determinados locais tinham por objetivo a convivência em Clusters notórios (sejam no processo produtivo, comercial e/ou tecnológico).

Os entrevistados, em sua maioria, não indicaram interesse em alterar os planos estratégicos e de investimentos quer no resto do país, quer no exterior, indicando que pretendem manter a maior parcela dos investimentos em Jaraguá do Sul. Entretanto, vários dos inquiridos alertaram para as dificuldades de infraestrutura que no município começa a dar sinais de esgotamento. No que se refere à hipótese de um eventual agravamento da situação de riscos para seus investimentos no Brasil e mesmo de certa restrição econômica decorrente de anúncios sobre ajustes na condução das contas públicas, os entrevistados consideram que a situação conjuntural não afetará seus planos de investimentos e que estes, a despeito de elevação das dificuldades externas não serão modificados. Mesmo assim, cabe destaque a quase unanimidade de redução da confiança sobre as possibilidades de crescimento nos próximos anos.

Por outro lado, deve-se destacar os aspectos positivos do município que perpassam pela qualidade de vida citada por boa parte dos entrevistados (exclusive as questões de mobilidade urbana, mesmo para uma cidade de pouco mais de 160 mil habitantes). A qualidade técnica da mão de obra é outro fator importante que foi mencionado. Contudo é importante mencionar que parte destes trabalhadores recebem treinamento na própria unidade fabril sendo necessária também uma rede de qualificação mais sofisticada que interaja nós vários níveis de ensino (fator destacado pelos empresários). 


\section{CONSIDERAÇÕES FINAIS}

A partir da pesquisa qualitativa junto aos empresários de Jaraguá do Sul foi possível perceber que a estrutura produtiva observada no município está acima da média nacional, seja em tamanha das plantas, base tecnologia ou mesmo na gestão empresarial e estratégica. Contudo, esse processo levou as empresas a tomarem decisões estratégicas que levaram a expansão das plantas para fora o espaço territorial de Jaraguá do Sul, tanto em outros municípios brasileiros quanto em outros países. No tocante a migração interna (municípios brasileiros) esta pode ser qualificada em três bases: 1) Busca de redução de custos (principalmente as plantas intensivas em mão de obra); 2) Incentivos fiscais, seja na esfera municipal, estadual ou federal (a exemplo de regiões da Sudene); e 3) Interação em Cluster especializados, em outras palavras ambientes de notório conhecimento comercial, produtivo ou tecnológico.

Já, no contexto da migração externa (internacionalização de capital), esta faz parte de um processo amplamente discutido na literatura especializada, e suas ações estão orientadas em um caminho de três fases. A primeira está relacionada a busca de novos mercados, assim o caminho da exportação é algo esperado por boa parte das empresas em expansão. Com a intensificação das exportações é percebido as oportunidades da segunda fase, a busca de centros de comercialização e produção em plantas próprias, o que auxilia na redução de custos provocados pelas barreiras comerciais (principalmente as tarifárias). Por fim, na terceira fase o ciclo está completo com a exportação não apenas do capital (na forma das plantas instaladas em outros países) como na da própria tecnologia. Vale ressaltar que as empresas que completaram esse caminho o fizeram antes de 2008 (crise financeira internacional), as que estão por completar aguardam a redução do ambiente de incerteza e das condições adversas observadas nos países de interesse, mas já estão avançados na segunda fase.

De toda sorte, ficou claro, pelo menos à curto prazo, a não intenção de mudança das matrizes do município, o que pôde ser observado pelo volume de investimento em Jaraguá do Sul e a especificidade deste, de base tecnológica avançada em comparação as demais plantas. Contudo, isso não exime o município da perda de capital investido por problemas mencionados na pesquisa. Entre as questões mencionadas estão os de infraestrutura, incentivos fiscais e custos de mão de obra. Por outro lado a qualidade de vida e qualificação da mão de obra observada no município é um fator positivo para a manutenção das matrizes, isso potencializado pelo aspecto tradicionalista das famílias fundadores das empresas. 
Por fim, destaca-se, em um aspecto geral (quantitativo e qualitativo), que deve-se ter reserva quanto a comparação entre o município de Jaraguá do Sul e outros do estado de Santa Catarina. Ao olhar esses municípios dá-se a impressão que os mesmos são parecidos, contudo, apresentam infraestrutura diferenciada (percebida a partir das entrevistas), assim como estrutura produtiva, apresentada com base nos dados quantitativos. Desta forma a comparação pode levar a expectativas que podem não ser atendidas, levado a frustração. Entre os diferenciais apresentados por Jaraguá do Sul pode-se citar a possibilidade da parceria entre o setor público e privado, exemplificado pela administração dos hospitais públicos.

\section{REFERÊNCIAS BIBLIOGRÁFICAS}

Atlas do Desenvolvimento Humano no Brasil. Consulta a espacialidade e indicador. Disponível em: http://www.atlasbrasil.org.br/2013/pt/consulta/. Acesso em 14 de fevereiro de 2015.

BBC. Crise muda perfil das exportações brasileiras. Reportagem de 9 de setembro, 2009. Disponível em: http://www.bbc.co.uk/portuguese/noticias/2009/09/090908_crise_exportacoes_ac_np.shtml. Acesso em 12 de fevereiro de 2015.

BONI, Valdete e QUARESMA, Sílvia Jurema. Aprendendo a entrevistar: como fazer entrevistas em CiênciasSociais. Revista Eletrônica dos Pós-Graduandos em Sociologia Política da UFSC. Vol. $2 \mathrm{n}^{\mathrm{o}} 1$ (3), janeiro-julho/2005, p. 68-80. Disponível em: https://periodicos.ufsc.br/index.php/emtese/article/viewFile/18027/16976. Acesso em 07 de fevereiro de 2015.

BRENE,Paulo Rogério Alves, SESSO FILHO, Umberto Antonio, COSTA, Armando João Dalla e RANGEL, Ronaldo Raemy. Estimativa da matriz de insumo-produto do município de São Bento do Sul no Estado de Santa Catarina. Revista Brasileira de Gestão e Desenvolvimento Regional G\&DR • v. 7, n. 3, p. 250-269, set-dez/2011, Taubaté, SP, Brasil. Disponível em: http://www.rbgdr.net/revista/index.php/rbgdr/article/viewArticle/526. Acesso em 15 de fevereiro de 2015.

CALLEGARI JACQUES, S. M. Bioestatística: princípios e aplicações. Porto Alegre; Artmed; 2003.

DINIZ, Clélio C. Desenvolvimento Poligonal no Brasil: nem desconcentração nem contínua polarização. Revista Nova Economia, Depto. Ciências Econômicas da UFMG, Belo Horizonte, v. 3, p.39, setembro de 1993.

FILHO, Dalson B. F. \& Silva Júnior, J. A. Desvendando os Mistérios do Coeficiente de Correlação de Pearson (r). Revista Política Hoje, Vol. 18, n. 1, p. 1-15 2009.

FIRJAN - Federação das Indústrias do Estado do Rio de Janeiro. Análise Especial IFDM 2011: Santa Catarina. FIRJAN: Rio de Janeiro, 2014. Disponível em: http://www.firjan.org.br/lumis/portal/file/fileDownload.jsp?fileId=2C908CEC462AE9DE014 64F3E91250B94. Acesso em 10 de fevereiro de 2015.

FIRJAN - Federação das Indústrias do Estado do Rio de Janeiro. Índice FIRJAN de Desenvolvimento Municipal (IFDM). Disponível em: http://www.firjan.org.br/ifdm/. Acesso em 01 de fevereiro de 2015.

GAZETADOPOVO. Índice é avanço sobre o IDH-M. Reportagem publicada em $11 / 08 / 2008$. 
http://www.gazetadopovo.com.br/vidaecidadania/conteudo.phtml?id=796198. Acesso em 14 de fevereiro de 2015.

IBGE - Instituto Brasileiro de Geografia e Estatística. Evolução e Perspectivas da Mortalidade Infantil no Brasil. Disponível em: http://www.ibge.gov.br/home/estatistica/populacao/evolucao_perspectivas_mortalidade/come ntarios.pdf. Acesso em 10 de fevereiro de 2015c.

IBGE - Instituto Brasileiro de Geografia e Estatística. Indicadores Sociais Mínimos. Disponível

em: http://www.ibge.gov.br/home/estatistica/populacao/condicaodevida/indicadoresminimos/conc eitos.shtm. Acesso em 10 de fevereiro de 2015b.

IBGE - Instituto Brasileiro de Geografia e Estatística. População residente - $\mathbf{1}^{\mathbf{o}}$ de julho estimativas (Jaraguá do Sul, Santa Catarina e Brasil). Disponível em: http://www.ipeadata.gov.br/. Acesso em 10 de fevereiro de 2015a.

Instituto Jourdan. Nota Técnica No 0002_V2_2014. Momento Econômico de Jaraguá do Sul - 1999 A 2012. Prefeitura de Jaraguá do Sul: Jaraguá do Sul, 2014. Disponível em: http://www.jourdan.org.br/wp-content/uploads/2014/12/NT-0002-Momento-

Econ\%C3\%B4mico-de-Jaragu\%C3\%A1-do-Sul.pdf. Acesso em 10 de fevereiro de 2015.

LESSA, Carlos. Um Rio de Sonhos: uma realidade para o Rio de Janeiro. Revista Archétypon, Rio de Janeiro, ano 6, n. 16, p. 29, jan/abr. 1998.

LIRA, S. A.; CHAVES NETO, A. Coeficientes de correlação para variáveis ordinais e dicotômicas derivados do coeficiente linear de Pearson. RECIE, Uberlândia, v. 15, n. 1/2, p. 45-53, jan.-dez. 2006. Disponível em: www.seer.ufu.br/index.php/cieng/article/download/529/489. Acesso em 06 de julho de 2013. MARCONI, Marina de Andrade e LAKATOS, Eva Maria. Fundamentos de metodologia científica. $5^{\text {a }}$. ed. São Paulo: Atlas, 2003.

MATTOS, Pedro Lincoln C. L. de. A entrevista não-estruturada como formade conversação: razões e sugestõespara sua análise. Revista de Administração Pública - RAP | EBAPE / FGV. Rio de Janeiro 39(4):823-47, Jul./Ago. 2005. Disponível em: http://bibliotecadigital.fgv.br/ojs/index.php/rap/article/view/6789/5371. Acesso em 07 de fevereiro de 2015.

MATTOSO, Jorge e POCHMANN, Marcio. Mudanças estruturais e trabalho no Brasil. Economia e Sociedade, Campinas, (10): 213-43, jun. 1998. Disponível em: https://www.google.com.br/url?sa=t\&rct=j\&q=\&esrc=s\&source=web\&cd=1\&cad=rja\&uact= 8\&ved=0CB0QFjAA\&url=http\%3A\%2F\%2Fwww.eco.unicamp.br\%2Fdocprod\%2Fdownarq .php\%3Fid\%3D478\%26tp\%3Da\&ei=wvLoVLyQDrDksATeioHQDQ\&usg=AFQjCNHy27W HQ3ZmJ7ynsbvlR_4HRJDCkw\&bvm=bv.86475890,d.cWc. Acesso em 10 de Fevereiro de 2015.

MDIC - Ministério do Desenvolvimento, Indústria e Comércio Exterior. Balança Comercial Brasileira por Município. Disponível em: http://www.mdic.gov.br//sitio/sistema/balanca/. Acesso em 14 de fevereiro de 2015.

MEURER, Roberto e SAMOHYL, Robert Wayne. Conjuntura econômica: entendendo a economia nodia-a-dia. Campo Grande, MS: Editora Oeste, 2001.

MOLLER, Horst Dieter e VITAL, Tales. Os impactos da crise financeira global 2008/09 e da crise na área de euro desde 2010 sobre a balança comercial brasileira. RACEF Revista de Administração, Contabilidade e Economia da Fundace. Edição: 07/2013, Ribeirão Preto, agosto de 2013. Disponível http://www.fundace.org.br/artigos_racef/artigo_03_07_2013.pdf. Acesso em 10 de fevereiro de 2015.

MOORE, David S. The Basic Practice of Statistics. New York: Freeman, 2007. 
MTE - Ministério do Trabalho e Emprego. Acesso online às bases estatísticas. Disponível em http://bi.mte.gov.br/bgcaged/login.php. Acesso em 12 de fevereiro de 2015.

PNUD - Programa das Nações Unidas para o Desenvolvimento. Atlas do Desenvolvimento Humano no Brasil. Disponível em: http://www.atlasbrasil.org.br/2013/pt/perfil_m/jaraguado-sul_sc. Acesso em 10 de fevereiro de 2015.

PONTES, Antonio Carlos Fonseca. Ensino da correlação de postos no ensino médio. $19^{\circ}$. SINAPE - Simpósio Nacional de Probabilidade e Estatística, Hotel Fazenda Fonte Colina Verde, São Pedro-S. 26 a 30 de julho de 2010. Disponível em: http://www.ime.unicamp.br/sinape/sites/default/files/EnsinoCorrelacaoDePostos.pdf. Acesso em 01 de fevereiro de 2013.

Prefeitura Municipal de São José do Rio Preto/SP. Planejamento Estratégico, Ciência, Tecnologia e Inovação: Conjuntura Econômica. Disponível em: http://www.riopreto.sp.gov.br/PortalGOV/do/subportais_Show?c=60202. Acesso em $20 \mathrm{de}$ janeiro de 2014.

SANDRONI, Paulo. Dicionário de Economia do Século XXI. São Paulo: Editora Record, 2005.

SEBRAE - Serviço Brasileiro de Apoio às Micro e Pequenas Empresa. Cenário de longo prazo para as MPE - Economia Internacional e Brasileira. Unidade de Capacitação Empresarial - UCE: Brasília, setembro de 2012. Disponívelem: http://www.sebrae.com.br/Sebrae/Portal\%20Sebrae/Estudos\%20e\%20Pesquisas/CES_setemb ro\%202012.pdf. Acesso em 15 de janeiro de 2014.

SEBRAE/SC - Serviço de Apoio às Micro e Pequenas Empresas de Santa Catarina. Santa Catarina em Números: Jaraguá do Sul. SEBRAE/SC: Florianópolis, 2010. Disponível em: http://www.sebrae-sc.com.br/scemnumero/arquivo/Jaragua-do-Sul.pdf. Acesso em 11 de fevereiro de 2015.

SIEGEL, S. e CASTELLAN, N. J. Estatística Não-Paramétrica para as Ciências do Comportamento. $2^{\circ}$ ed. Porto Alegre: Bookman, 2006.

WOLFFENBÜTTEL, Andréa. O que é? - Índice de Gini. Revista Desafios do DesenvolvimentoInstituto de Pesquisa Econômica Aplicada - Ipea.Ano 1 . Edição 4 $1 / 11 / 2004$.

Disponível

em: http://desafios.ipea.gov.br/index.php?option=com_content $\&$ view $=$ article $\&$ id=2048: catid=28 \&Itemid=23. Acesso em: 14 de fevereiro de 2015.

Trânsito é o que mais afeta qualidade de vida do carioca, diz pesquisa. Reportagem do Bom Dia Brasil. Edição do dia 27/11/2013. Disponível em: http://g1.globo.com/bom-diabrasil/noticia/2013/11/transito-e-o-que-mais-afeta-qualidade-de-vida-do-carioca-dizpesquisa.html. Acesso em 08 de março de 2015.

Recebido em 11 de outubro de 2017. Aceito em 24 de novembro de 2017. 